http://journal.nafo.int

J. Northw. Atl. Fish. Sci., Vol. 10: 1-51

\title{
The Delimitation of Fishing Areas in the Northwest Atlantic
}

\author{
R. G. Halliday \\ Department of Fisheries and Oceans, Biological Sciences Branch \\ P. O. Box 1006, Dartmouth, Nova Scotia, Canada B2Y 4A2 \\ and \\ A. T. Pinhorn \\ Department of Fisheries and Oceans, Science Branch \\ P. O. Box 5667, St. John's, Newfoundland, Canada A1C 5X1
}

\begin{abstract}
The delineation of geographic areas for the purpose of collecting fisheries statistics (referred to as "fishing areas") in the Northwest Atlantic is described from the first division by the North American Council on Fishery Investigations in the early-1930s, through development of the International Commission for the Northwest Atlantic Fisheries statistical system in the early-1950s, to the present Northwest Atlantic Fisheries Organization (NAFO) system. The bases for these fishing areas are examined, and, in particular, knowledge of biological stock structure at crucial decision points is reconstructed, to determine the extent to which fishing areas were designed to correspond to stock distribution areas of the important commercial species. This correspondence is also examined in the light of present knowledge of stock structure. It transpires that only cod and haddock stock structure is documented as being influential in statistical boundary determination.

The present NAFO statistical grid system could be improved, particularly by incorporation of the boundaries between coastal state and NAFO Regulatory Area waters, but is basically too inflexible to serve the needs of diverse modern fisheries. A hierarchical system, with the basic unit being a $10^{\prime}$ or $15^{\prime}$ graticule, as has already been adopted by some countries for domestic statistics, should be established in the international context of NAFO to promote regional science and management initiatives. Biologists need to define more precisely the correspondence required between stock and management areas for the effective control of exploitation rates.
\end{abstract}

\section{Introduction}

The first subdivision of the Northwest Atlantic for the purpose of collecting fishery statistics by area of capture was made by the North American Council on Fishery Investigations (NACFI) in the early-1930s. The NACFI statistical grid was modified and greatly elaborated by the International Commission for the Northwest Atlantic Fisheries (ICNAF) after 1950. On replacement of ICNAF with the Northwest Atlantic Fisheries Organization (NAFO) in 1979, responsibility for compilation and maintenance of statistical records for the region fell upon the Scientific Council of NAFO (under Article VI.1(b) of the Convention). The Food and Agriculture Organization of the United Nations (FAO) has also had a substantial influence on the development of the Northwest Atlantic statistical system through its support of the Continuing Working Party on Fishery Statistics in the North Atlantic Area, now called Coordinating Working Party on Atlantic Fishery Statistics (CWP). This Working Party was established on the basis of a recommendation by an Expert Meeting on Fishery Statistics in the North Atlantic Area sponsored by FAO in 1959 (FAO, 1962). 
The term "fishing area" was adopted by the CWP as a general descriptive term for any geographic area delineated for the purpose of collecting fisheries statistics (FAO, 1963). The present paper describes the history of fishing area delimitation in the Northwest Atlantic which has culminated in the present day NAFO statistical grid. The various reasons underlying the decisions for the placement of statistical demarcation lines are analyzed, particularly correspondence with fish stock boundaries which supposedly has been a primary consideration in establishing the positions of statistical lines. The results are discussed in the context of present scientific knowledge, of accumulated experience in fisheries management using the NAFO statistical grid, and of current fisheries management problems. What are described, therefore, are the actions of international agencies to establish regional systems of fishing areas so that comprehensive fishery statistics would be available for research and management purposes. Coastal states also have developed fine scale statistical grids for domestic purposes. These are not described in detail but it has been necessary to illustrate them to adequately portray scientific views on fishing area delineation. The conventions of ICNAF and NAFO have placed an obligation on Contracting Parties to report statistics by the fishing areas these conventions have defined. This obligation has been to provide comprehensive data on the nominal catch of each species, and on the amount of fishing conducted, by specified vessel and gear categories on a monthly basis.

The term "stock" is used here to mean a self-sustaining population of a species, i.e. a biological rather than a managerial definition is adopted. The Northwest Atlantic fisheries literature is not usually explicit about the definition used but there seems little doubt that this definition has been the one commonly underlying discussion of "stocks". Stock structure, therefore, is a description of the spatial and temporal separation of a species into relatively discrete reproductive units. This is referred to as population pattern by Sinclair (1988), who also refers to the number of stocks within a species as its population richness. In a managerial context, the term stock has sometimes meant little more than the fish which happen to be within a defined management unit, but more usually it has meant a group of fish which can be treated as if it was a biological stock for some particular management purpose, i.e.the "unit stock" of Gulland (1983). To avoid confusion, reference to such a group of fish defined for management purposes is avoided entirely. The designations "management area" or "management unit" are used to refer to a geographic area defined for regulatory purposes.

Place names mentioned in the text are illustrated in Fig. 1 and 2. The remaining figures, which illustrate proposed or adopted statistical or management boundaries, are all extracted from the documents or publications in which they first appeared. This avoids introduction of drafting errors. It also seems appropriate to allow readers to examine directly the illustrations available at the times when decisions were being made. A chronology of the major changes in fishing area boundaries is given in Appendix 1.

\section{History of Fishing Area Delimitation}

\section{NACFI Statistical Areas}

The USA began to record area of capture by fishing ground for landings at major Atlantic coast ports in 1891 (Rounsefell, 1948). Although these grounds were illdefined until Rich's (1929) descriptions in the 1920s, the system provided substantial detail on area of capture. In contrast, when Canadian fisheries statistics first reflected 
HALLIDAY and PINHORN: Delimitation of Fishing Areas

3

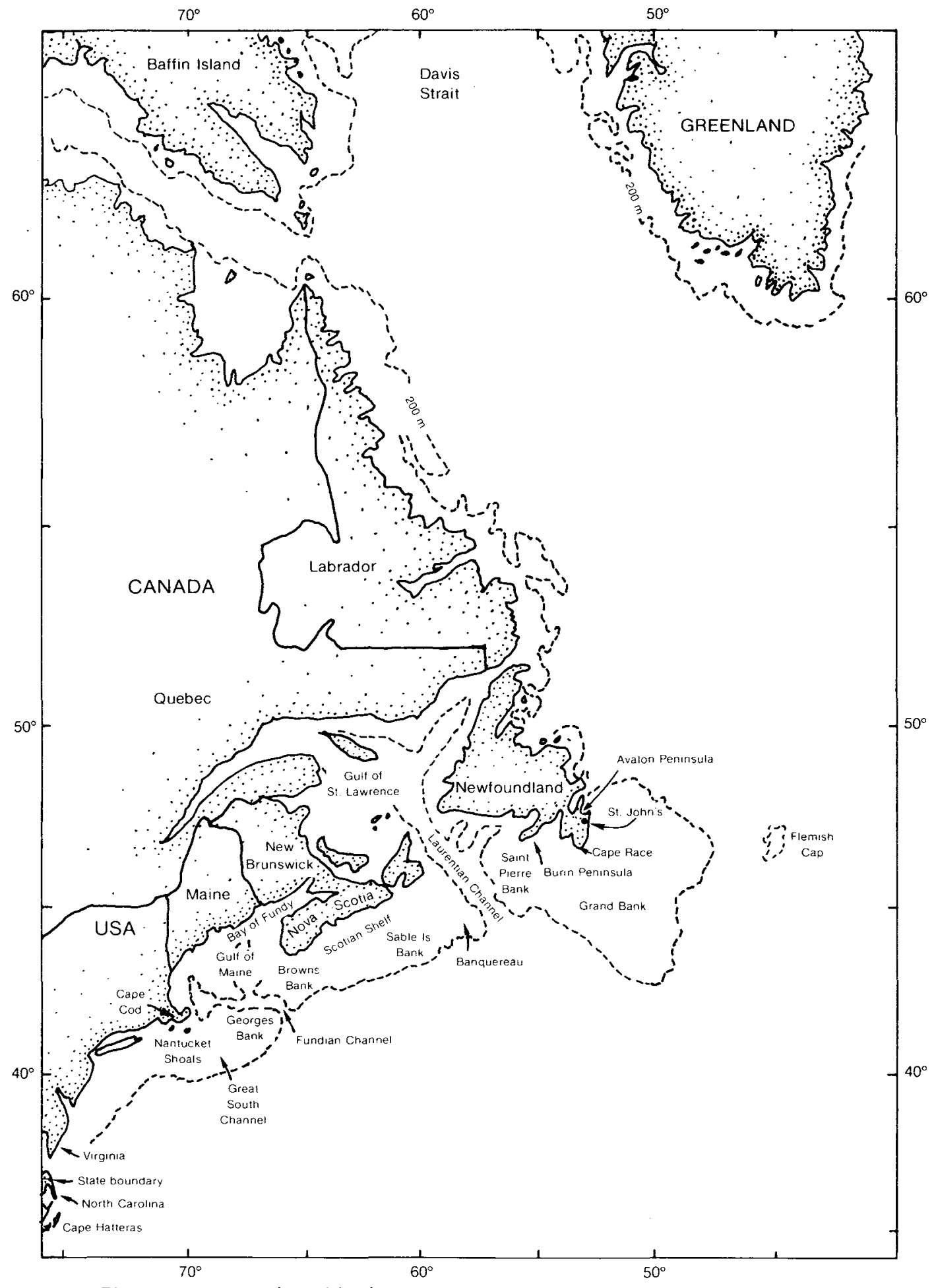

Fig. 1. Place names mentioned in the text. 


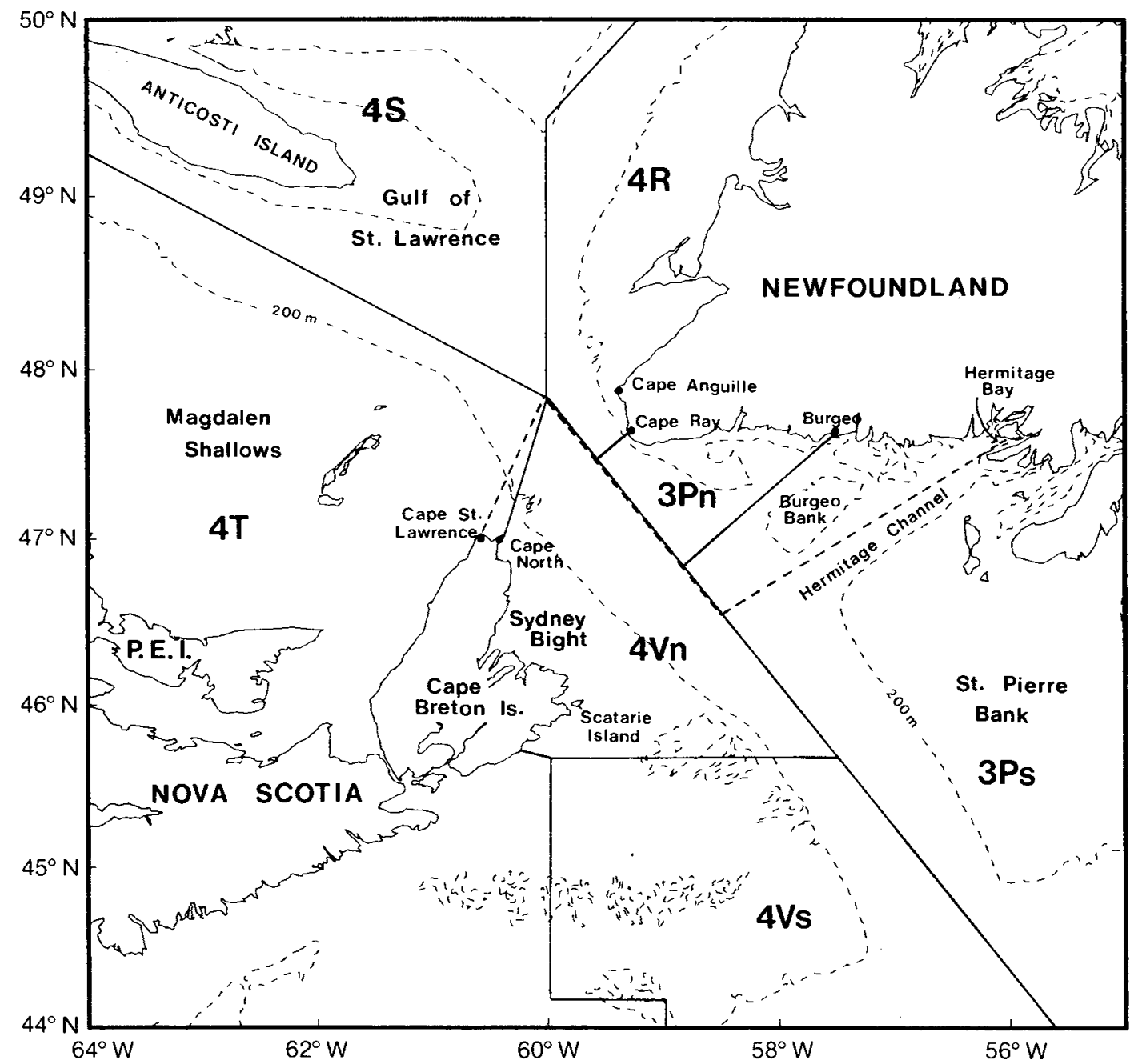

Fig. 2. Place names at the southern entrance to the Gulf of St. Lawrence mentioned in the text, with a comparison of NACFI (dashed lines) and ICNAF/NAFO (solid lines) statistical boundaries in this area.

area of capture in 1917 only catches from inshore and offshore areas were distinguished (Canada, 1920; Needler, undated). The first steps to establish a common international system of collection of area of capture information were taken by NACFI at its first meeting in 1921. This council (which underwent several name changes between 1921 and 1930) was established, by agreement of the governments of Canada, Newfoundland and the USA, to promote and coordinate marine fishery research in the Northwest Atlantic. France joined in 1922. It was not until 1932, however, that a chart defining statistical areas (Fig. 3) was agreed upon (NACFI, 1935). This chart covered the area from Greenland to the Lesser Antilles. The numbering system adopted for the various "regions" defined by the chart followed sequentially those established by the International Council for the Exploration of the Sea (ICES) for the Northeast Atlantic (ICES, MS 1982), reflecting coordination with ICES in this endeavour. The chart was proposed as the minimum subdivision required to provide statistics suitable for scientific investigations on the fisheries, but NACFI did not document the reasons for the particular subdivision chosen". However, Found (1933) stated that "the limits have been designed to correspond as far as possible with natural divisions of the fish populations or with barriers to fish migrations".

Minutes of NACFI meeting, Canadian Government archives. 


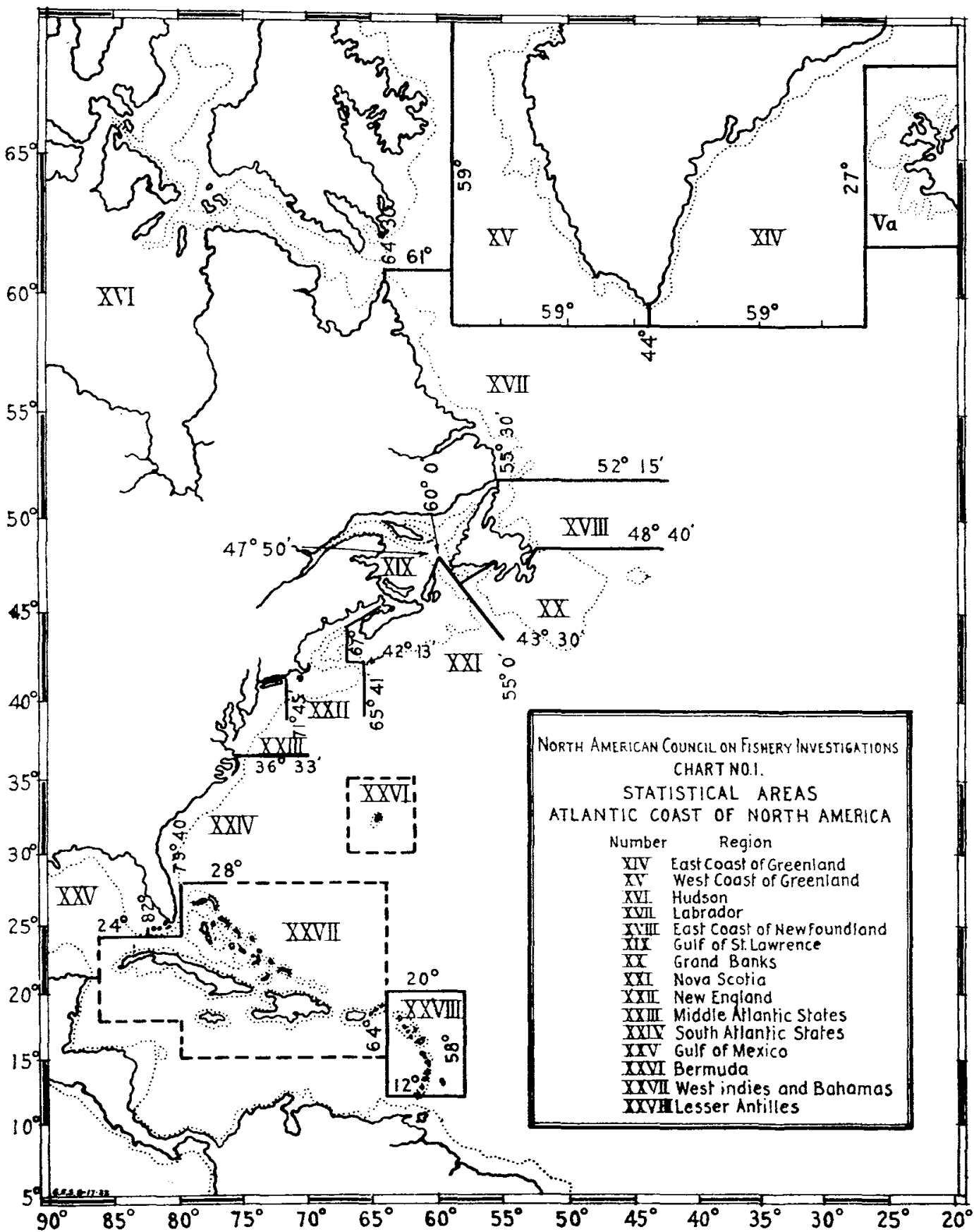

Fig. 3. North American Council on Fishery Investigations Chart No. 1 - Statistical Areas, Atlantic Coast of North America (from NACFI, 1935).

The only adjustments made to the NACFI system subsequent to its adoption concerned the line between Nova Scotia and New England regions (Rounsefell, 1948). The first of these adjustments, made in 1936, moved this line to run through the deepest parts of the Fundian Channel (from $42^{\circ} 13^{\prime} \mathrm{N}$ to $42^{\circ} 20^{\prime} \mathrm{N}$ ) and Gulf of Maine $\left(67^{\circ} 00^{\prime} \mathrm{W}\right.$ to $\left.67^{\circ} 40^{\prime} \mathrm{W}\right)$, apparently to better separate fishing areas for haddock (Melanogrammus aeglefinus) (Halliday et al., 1986). The second change, made unilaterally in 1943 by the USA as NACFI had ceased to function after 1939 as a result of the 
Second World War, changed the northern end of the line to coincide with the terminus of the international land boundary between the USA and Canada, placing all of the Bay of Fundy on the eastern side of the line. This appears to have been an administrative convenience (Rounsefell, 1948).

Scientists, particularly those from the USA, recognized the need for a finer scale breakdown of catch and fishing effort statistics for scientific purposes. Coincident with development of the NACFI regional grid, USA scientists established a recording system on the scale of individual fishing banks or fishing grounds (Rounsefell, 1948). This differed from that described by Rich (1929) in using areas defined precisely by latitude and longitude. There is no record of NACFI formally adopting this "subarea" system (although Rounsefell refers to NACFI adoption of revisions to it in 1936 and 1939). It has, however, played an important role as the basic geographical grid in the USA and Canadian statistical collection systems.

In his description of this fine-scale system, Rounsefell (1948) gave the first extensive explanation of the reasons for collecting fishery statistics by small geographical areas. He wrote that the primary purpose for obtaining accurate commercial fishery statistics was to determine trends in abundance of marine species from year to year. This was in order to determine the proper level at which to maintain fish populations to obtain the maximum sustainable yield. He points out that the areas covered by the fishing fleets are not homogeneous and that:

"Each species of fish is normally most abundant on the banks most suitable to it. Different stocks of the same species may inhabit two neighbouring banks, yet be separated by waters of such depths or temperature, or by such unsuitable bottom, that the two stocks mingle slightly or not at all.

Such Barriers to free migration change the problem from the simple one of sampling a single population to the vastly more complex one of sampling a series of populations ..."

He then emphasized the need for a stratified sampling scheme requiring the delineation of areas homogeneous with regard to fish density as the basic sampling units for the collection and analysis of fishery statistics.

Rounsefell thus captured the concepts, and some of the complexities, of measuring fish densities as indicators of abundance and of the need to work with biological stock units in analysis and management.

\section{The ICNAF Area}

The first comprehensive international conservation convention for North Atlantic fisheries titled the International Convention for the Regulation of the Meshes of Fishing Nets and the Size Limits of Fish was concluded in London, England in 1937. It applied to the area north of the equator from $80^{\circ} \mathrm{E}$ to $80^{\circ} \mathrm{W}$, and thus included the Northwestern Atlantic. However, no American countries were party to that convention which, in any case, did not come into legal effect. A second conference in London, England in 1943 resulted in the Draft Convention relating to the Policing of Fisheries and Measures for the Protection of Immature Fish, which pertained to an area north of the Tropic of Cancer and as far west as $75^{\circ} \mathrm{W}$. North American coastal states had doubts that their interests would be well served in an Atlantic-wide convention numerically dominated by European nations ${ }^{2}$. The USA, which sent observers only to the conference, considered that any convention should apply only to waters east of $40^{\circ} \mathrm{W}$.

${ }^{2}$ Minutes of the International Fisheries Conference, London, England, 1943, Canadian Government archives. 
Canada participated and addressed North American concerns by having a resolution included in the Final Act proposing the establishment of a Special Area which had an undetermined eastern boundary somewhere between $40^{\circ} \mathrm{W}$ and $43^{\circ} \mathrm{W}$, a western boundary of $75^{\circ} \mathrm{W}$, and which lay north of $40^{\circ} \mathrm{N}$. It was further proposed that this area be regulated by a Northwestern Atlantic Fisheries Organization within the broader convention. Canada, Newfoundland and USA would be recognized as having "special geographic and economic interests" in this area. The 1943 conference was viewed as preparation for conclusion of a post-war convention. However, by the time a third conference was held in London, England in 1946, views had crystallized that separate solutions to conservation issues in the eastern and western North Atlantic were preferable and it was decided to restrict consideration at this 1946 conference (which resulted in establishment of the Permanent Commission) to the area east of $42^{\circ} \mathrm{W}$, apparently at the suggestion of the USA (ICNAF, 1951). A conference convened in Washington, D.C., USA, in January 1949 formulated and opened for signature the International Convention for the Northwest Atlantic Fisheries. This Convention entered into force on 3 July 1950, the stated purpose being "the investigation, protection and conservation of the fisheries". The first meeting of the resulting International Commission for the Northwest Atlantic Fisheries took place in April 1951, also in Washington, D.C., USA. Choice of an eastern boundary for the ICNAF Convention Area of $42^{\circ} \mathrm{W}$, coincident with the western boundary of the Permanent Commission, was an act of administrative tidiness which ensured that all the northern North Atlantic was encompassed by one commission or the other ${ }^{3}$.

The boundary between eastern and western Atlantic Convention Areas at $42^{\circ} \mathrm{W}$ represented a compromise which placed, to the extent possible, European fisheries at East Greenland in the European sphere while not encroaching on the western Atlantic fishing banks at lower latitudes. The southern tip of Greenland is at $44^{\circ} \mathrm{W}$ whereas the eastern slope of Flemish Cap is at $43^{\circ} \mathrm{W}$.

With regard to the western boundary of the ICNAF Convention Area, $71^{\circ} 40^{\prime} \mathrm{W}$ was chosen, although the 1937 and 1943 conferences had proposed western limits to their conventions at $80^{\circ} \mathrm{W}$ and $75^{\circ} \mathrm{W}$ respectively. The ICNAF boundary approximated the NACFI line between areas XXII and XXIII $\left(71^{\circ} 45^{\prime} \mathrm{W}\right)$ but corresponded exactly to the dividing line between these areas as used in the "subarea" system (Rounsefell, 1948). Conservation of traditional groundfish resources, particularly cod (Gadus morhua) and haddock was the motivating factor for the ICNAF convention and $71^{\circ} 40^{\prime} \mathrm{W}$ described the western limit of the haddock fishery (Rounsefell, 1948).

Although the southern limit of application of the draft convention of 1943 was the Tropic of Cancer $\left(23^{\circ} 27^{\prime} \mathrm{N}\right)$, the "special area" in the Northwest Atlantic proposed by Canada had a southern limit of $40^{\circ} \mathrm{N}$, again reflecting that the traditional groundfish fisheries were the focus of attention. In the ICNAF convention, however, the southern boundary of the area was taken as $39^{\circ} \mathrm{N}$ so as to include the continental slope south of Georges Bank and Nantucket Shoals ${ }^{4}$.

With regard to the northern limit of the ICNAF Convention Area, the draft convention placed before the 1949 Washington, D. C. conference by the USA included NACFI area XV (West coast of Greenland) but not area XVI (the Hudson Region) (Fig. 3$)^{5}$. The USA proposal included in the Convention Area the west coast of Greenland to $59^{\circ} 00^{\prime} \mathrm{W}$, which occurs at about $76^{\circ} \mathrm{N}$ in Melville Bay (Fig. 4). During the conference

${ }^{3}$ Except for a small area north of $59^{\circ} \mathrm{N}$ and between $42^{\circ} \mathrm{W}$ and $44^{\circ} \mathrm{W}$ off the south coast of Greenland. This was included in the North-East Atlantic Fisheries Convention Area in 1959.

4 Correspondence files, Canadian Government archives.

5 Minutes of the International Northwest Atlantic Fisheries Conference, Washington, D.C., USA, 1949, Canadian Government archives. 


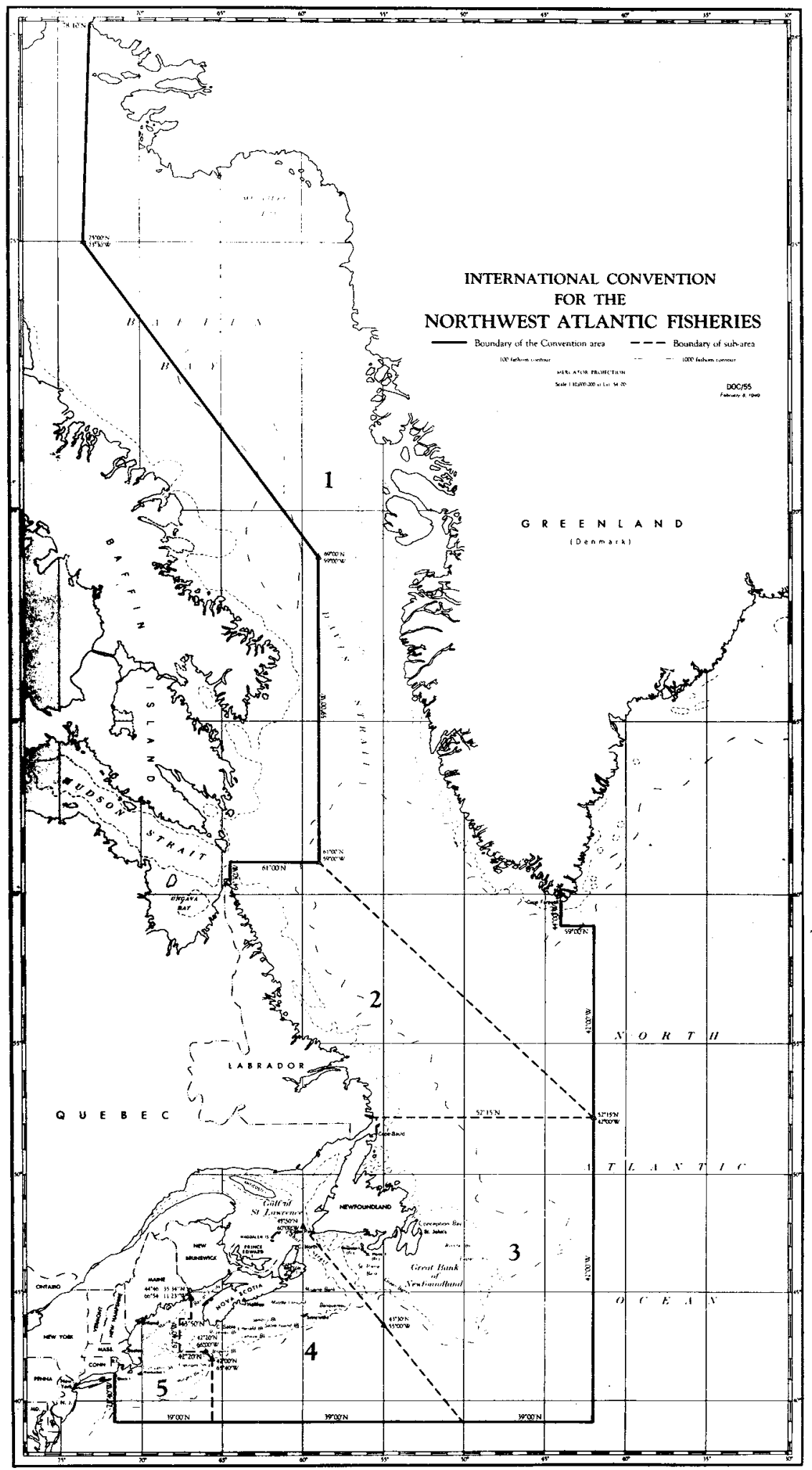

Fig. 4. Chart of the area of the Northwest Atlantic and the five Subareas thereof covered by the International Convention for the Northwest Atlantic Fisheries (from ICNAF, 1951). 
Denmark was instrumental in having the proposed Convention Area extended to include northwestern Greenland to $78^{\circ} 10^{\prime} \mathrm{N}$ (and $73^{\circ} 30^{\prime} \mathrm{W}$ ) on the basis that fisheries, particularly for Greenland shark (Somniosus microcephalus), were developing in these waters, and the need for investigation and possible later protection of such species was foreseen ${ }^{5}$.

The coastal limit to the Convention Area was the limit of territorial waters of coastal states. For statistical purposes ICNAF made no distinction between the Convention Area and territorial waters. It was not until 1962 (ICNAF, 1962) that the terminology "ICNAF Statistical Area" was adopted to clarify that statistics included those for territorial waters as well as for the Convention Area. The distinction between Statistical and Convention Area catches became problematical with the advent of national allocation of total allowable catches (TACs) in the early-1970s. ICNAF could set catch limits for the Convention Area only. Expected catches in territorial waters, which in 1949 had extended to 3 nautical miles from the coast, had to be estimated (e.g. Canada, MS 1972) so that they could be subtracted from TACs, set on the basis of stocks. It was only after these catches expected to be taken outside the Convention Area had been "taken off the top" that the remaining parts of the TACs could be allocated by ICNAF as controls on catches within the Convention Area (e.g. ICNAF, 1972a).

Thus the bounds of the ICNAF Area (Fig. 4) were determined based on the political realities of territorial claims and the political aspirations of Northwest Atlantic coastal states to have a strong, or even predominant, voice in regulation of fisheries off their coasts. The distribution of the North Atlantic groundfish fisheries, particularly for cod and haddock, was also of major influence in defining southern and western limits.

\section{The ICNAF Subareas}

The NACFI areas (Fig. 3) clearly had a strong influence on the definition of ICNAF Subareas. In consultations prior to the 1949 Washington, D.C. conference ${ }^{6}$, Canada, Newfoundland and the USA had agreed to propose a Subarea corresponding to the NACFI New England Region (XXII) (incorporating Rounsefell's (1948) modifications to both northeastern and southwestern boundaries), a Subarea incorporating Gulf of St. Lawrence and Nova Scotia regions (XIX and XXI) (but excluding the southwest coast of Newfoundland which had been in XIX), a Subarea incorporating the East Coast of Newfoundland and Grand Banks regions (XVIII and XX), and a Subarea incorporating the West Coast of Greenland and Labrador regions (XV and XVII). Only the most northern proposed Subarea became an issue at the 1949 conference with Denmark pointing out that West Greenland waters were most closely connected oceanographically and biologically, at least in the case of cod, with more eastern waters whereas Labrador cod were most closely connected with Newfoundland cod. Thus a new boundary was defined (Fig. 4) separating West Greenland (as ICNAF Subarea 1) from Labrador (as ICNAF Subarea 2). The remaining Subareas proposed were incorporated unchanged in the final convention as ICNAF Subareas 3-5.

It was the intent that Subareas would serve as the geographical basis for Panels within the proposed Commission, these Panels being responsible for proposing conservation actions ${ }^{5}$. Hence homogeneity of fisheries, and particularly fisheries participation, with a key factor in definition of Subareas. It was thought on the one hand that

\footnotetext{
${ }_{5}$ Minutes of the International Northwest Atlantic Fisheries Conference, Washington, D.C., USA, 1949, Canadian Government archives.

- Correspondence files, Canadian Government archives.
} 
these Subareas should be in sufficient numbers that problems in each region could be dealt with effectively solely by those parties having a primary interest in that regional fishery, while on the other hand they should be as large as possible so that regulations would be homogenous over wide areas thus minimizing enforcement problems.

\section{The ICNAF Divisions}

By the 2nd Annual Meeting of ICNAF in 1952 the value of collecting statistics by units smaller than Subareas was brought to the attention of the Commission (ICNAF, MS 1952a). Specific proposals were made by the ICNAF Standing Committee on Research and Statistics (STACRES) to adopt the already developed "subarea" system for Subareas 4 and 5 and similarly detailed breakdowns of Subareas 1-3 which had been prepared for, or at, the 1952 meeting (ICNAF, MS 1952b). The Commission tentatively accepted the proposed subdivisions but, during the subsequent year, the view developed that collection of accurate statistics by units as small as these was impractical (except in the case of Subarea 1, the subdivision of which was retained). At the 1953 meeting, therefore, the Commission adopted, effective 1 January 1954, the larger subdivisions (Fig. 5) which, with only minor modification, provided the basis for statistics collection throughout the life of the Commission (ICNAF, MS1953a). The various proposals for subdivision of Subareas made in 1952-53 are illustrated in Fig. 6-11 (ICNAF, MS 1952a, MS 1953b; Templeman and Fleming, MS 1953). These are discussed below.

The thinking behind the choice of scale for subdivisions is outlined in most detail by the Commission Statistician (Côté, MS 1953). Subdivision was mainly to be governed by the needs of biologists for catch and fishing effort data which reflected the abundance of stocks. Thus area subdivisions should delimit stocks. However, Côté goes on to say that from a biological viewpoint there would be no need to subdivide "a homogeneous area inhabited by one and the same stock". Côté equates such an area with a "natural habitat" and states that:

"An ideal division of Subareas in subunits would be made by consideration of:

1. the bottom condition of the area (including depth)

2. the hydrographic conditions

3. the knowledge of the distribution of the stock[s] and their migration.

It may be that areas traditionally fished should also be considered without jeopardizing biologists needs".

Côté also emphasized the need for long term constancy in area boundaries and that more accurate statistics can be provided for large areas than for small ones.

Côté's view differed from that of Rounsefell (1948) by emphasizing homogeneity of areas in terms of stock composition and relegating fishery distribution to a side issue. In contrast Rounsefell considered it important to define areas homogeneous with respect to fish density largely as demonstrated by fishery concentrations. This dichotomy of views presaged numerous future debates.

Detailed rationales for the choice of each subdivision boundary are not available but the general principles used (ICNAF, MS 1953a) emphasize practicality:

"1. Uniformity of size of subdivisions throughout the area.

2. Division of important fishing grounds and fish stocks. 


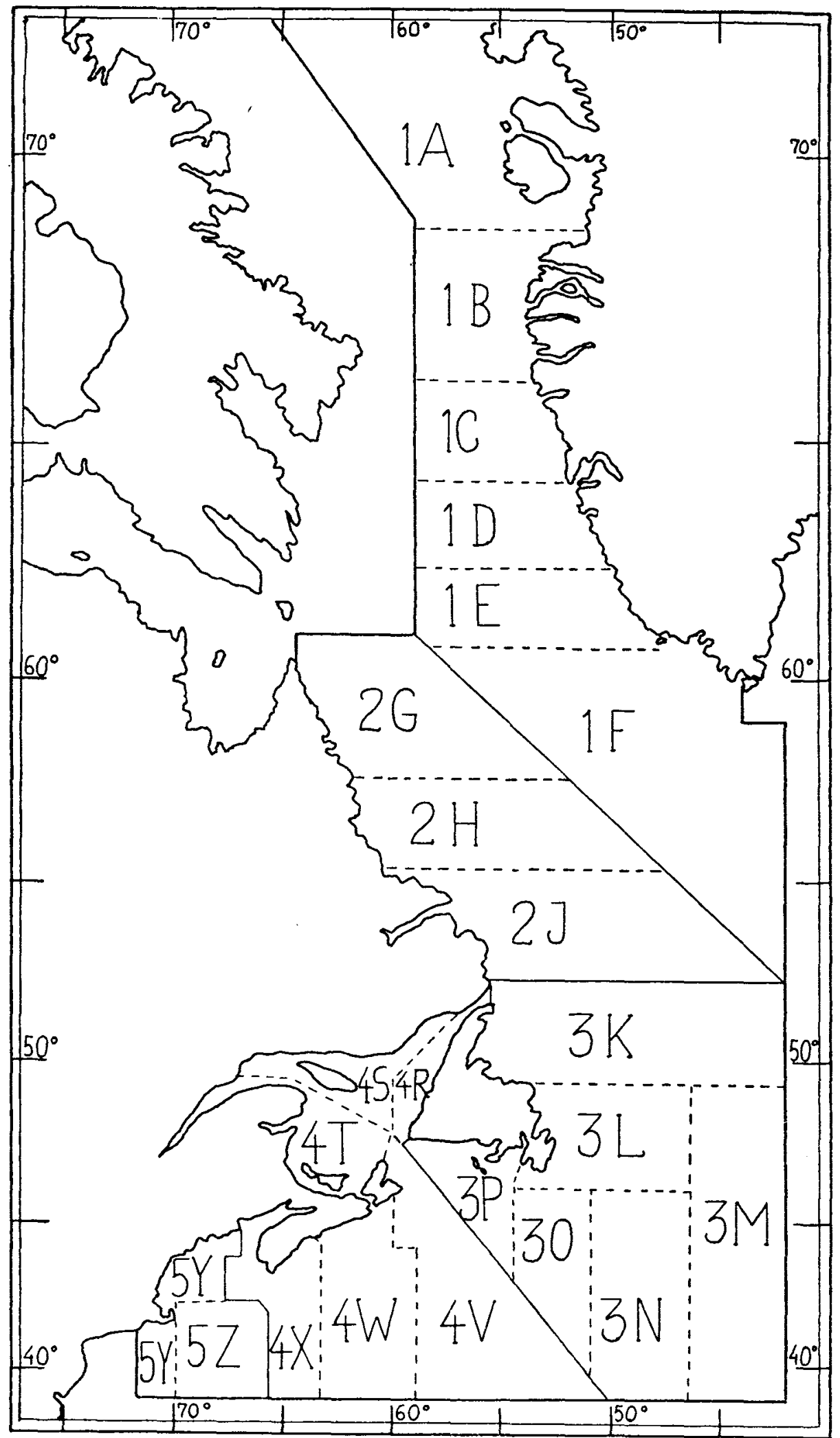

Fig. 5. Map of Subdivisions (renamed Divisions in 1960) of the Convention Area produced in ICNAF Statistical Bulletin Vol. 3 for 1953 (1955). Note that dividing line between $5 Y$ and $5 Z$ extends south of Cape Cod at $70^{\circ} \mathrm{W}$. 


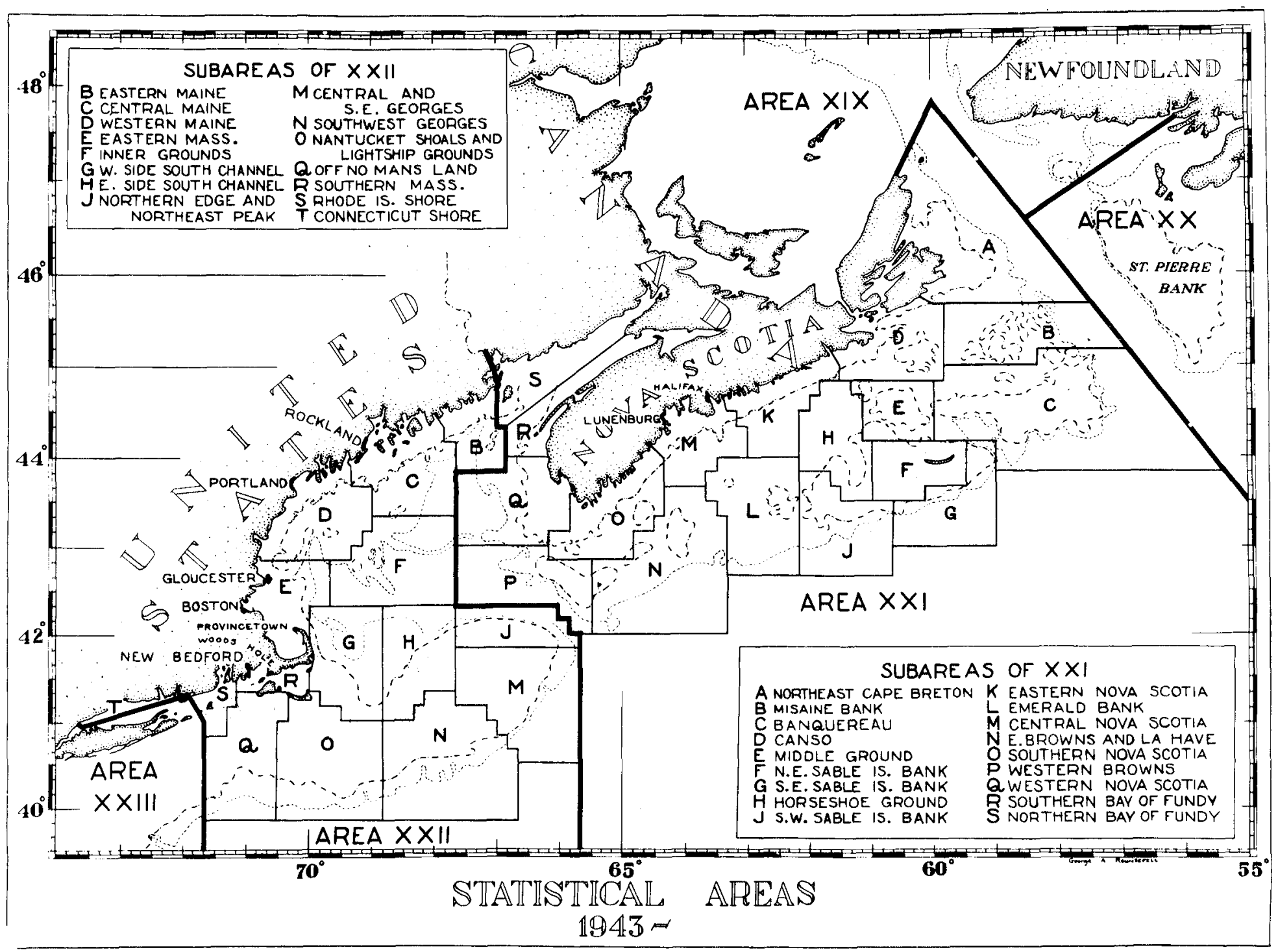

Fig. 6. Revised statistical "subareas" adopted by the USA in 1943 for the Nova Scotia and New England regions (from Rounsefell, 1948) and tentatively accepted as ICNAF subdivisions in 1952. 


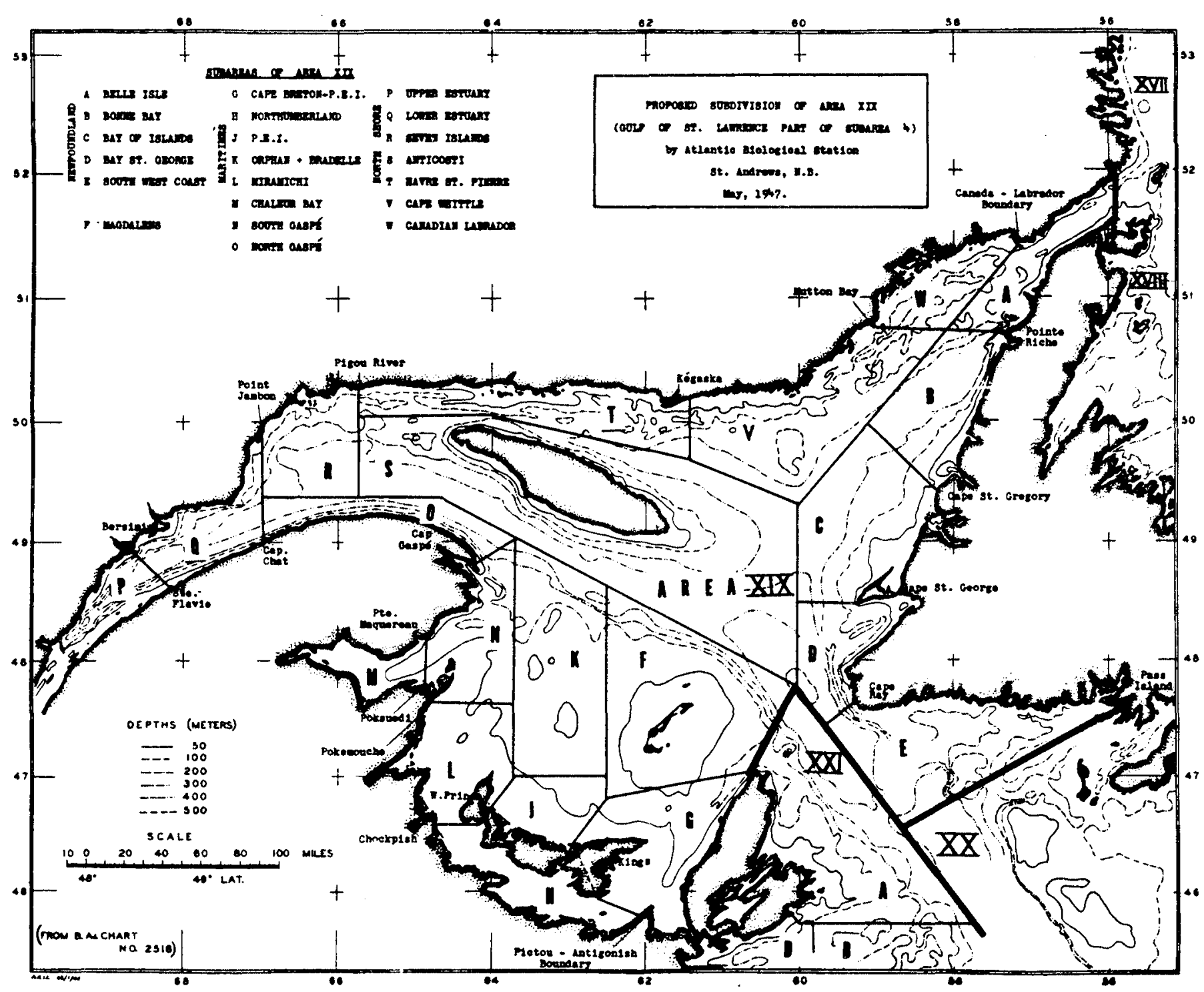

Fig. 7. Statistical "subareas" adopted by Canada for the Gulf of St. Lawrence Region in 1947 and tentatively accepted as ICNAF subdivisions in 1952 (from ICNAF, MS 1952a). 


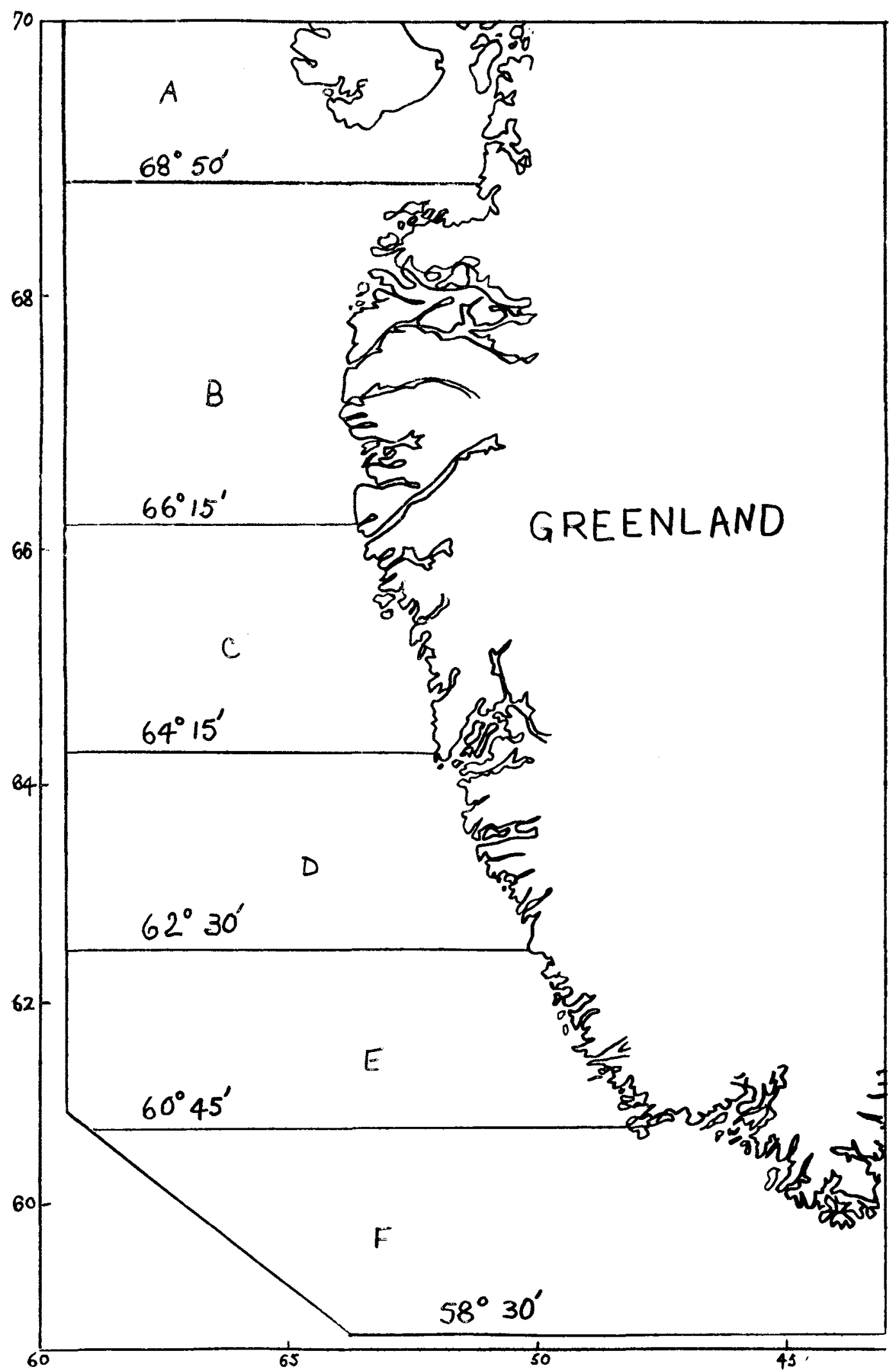

Fig. 8. Statistical subdivisions of Subarea 1 tentatively accepted by ICNAF in 1952 (from ICNAF, MS 1953b). The line at $58^{\circ} 30^{\prime} \mathrm{N}$ was dropped at the time of final acceptance in 1953 (ICNAF, MS 1953a). 


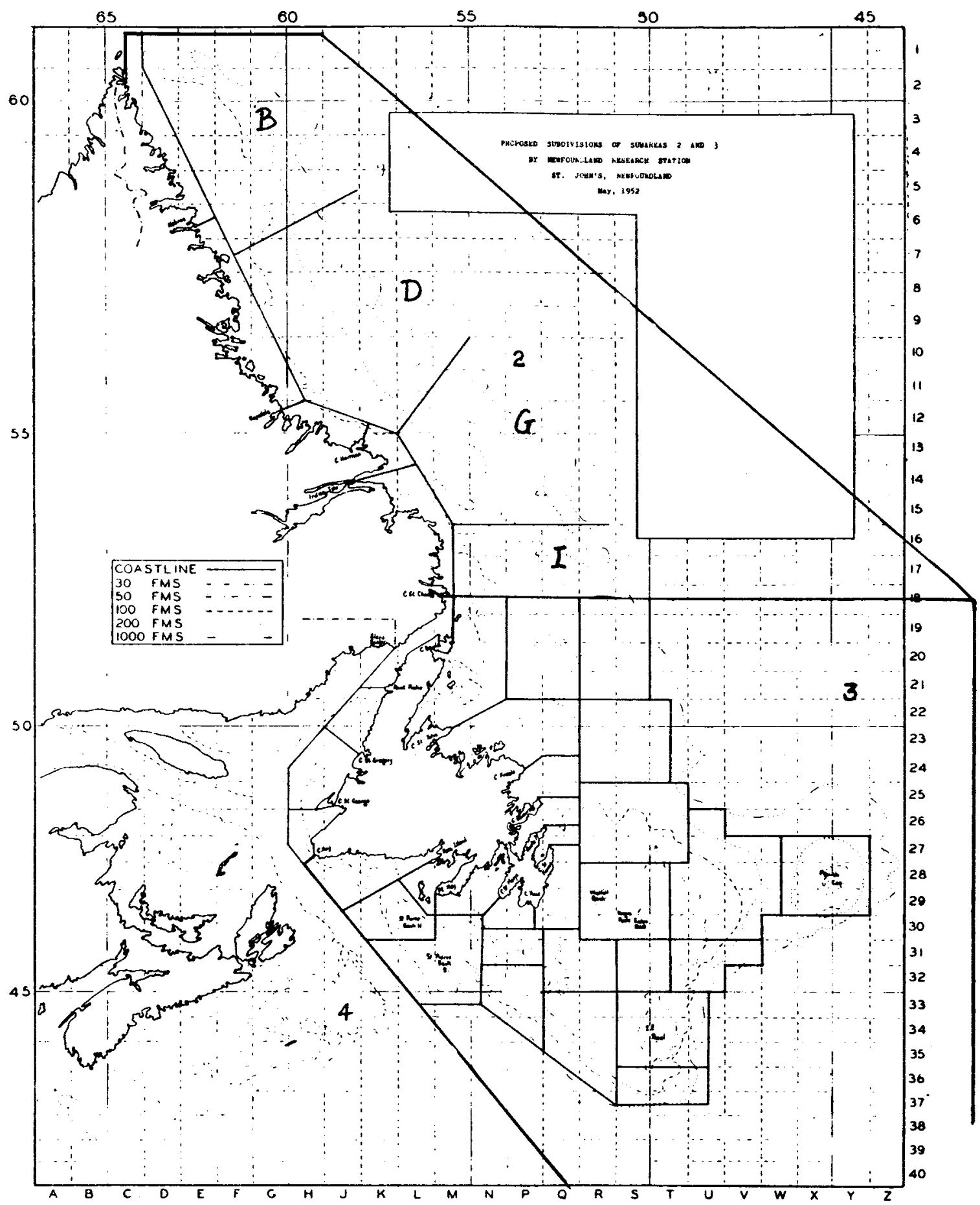

Fig. 9. Statistical subdivisions of Subareas 2 and 3 proposed by the Newfoundland Fisheries Research Station in 1952 (from ICNAF, MS 1952a). Those for Subarea 2 were tentatively accepted by ICNAF in 1952, with addition only of the letter designations superimposed on the original proposal (ICNAF, MS 1953b) as has been done above. 


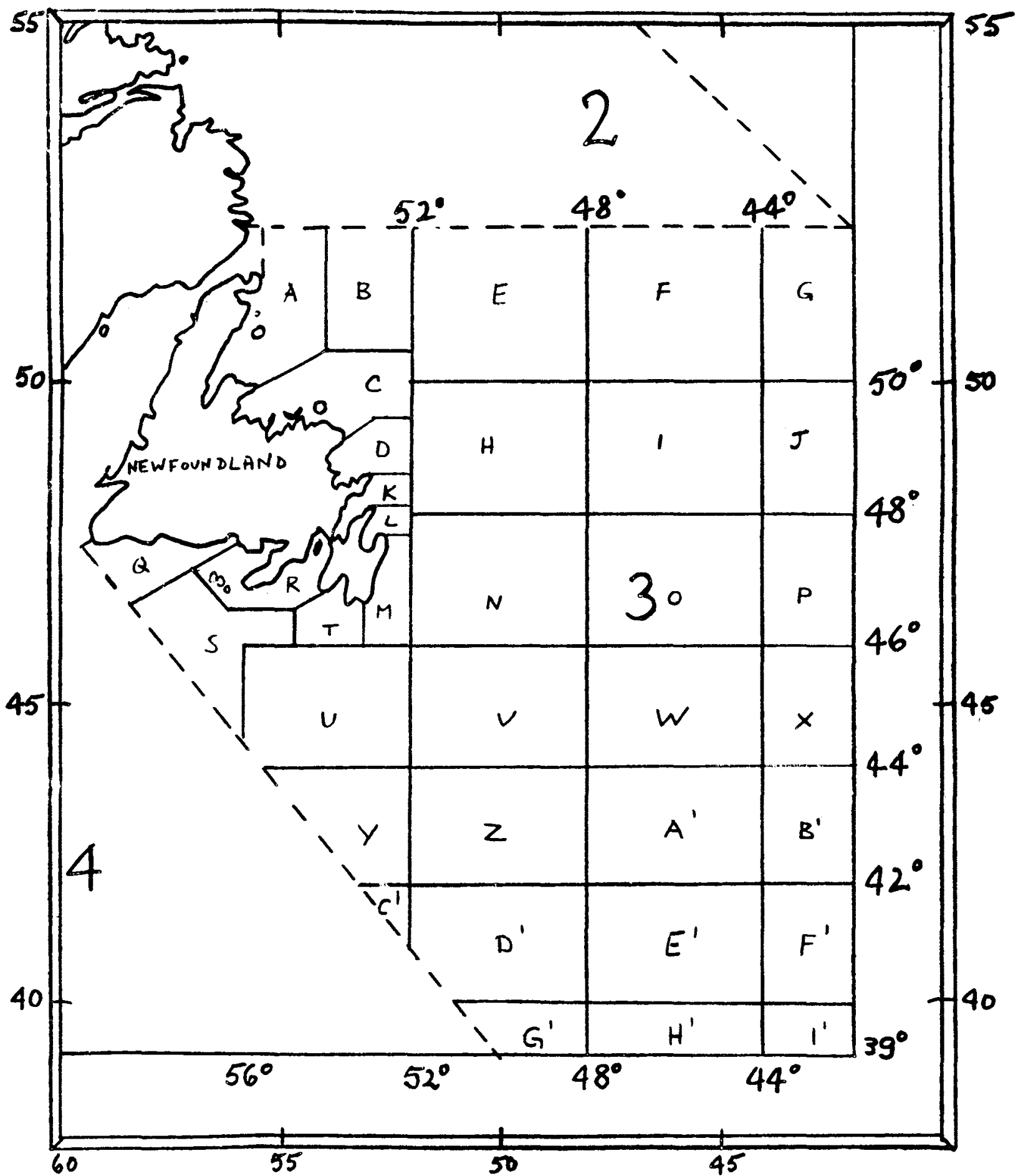

Fig. 10. Statistical subdivisions of Subarea 3 tentatively accepted by ICNAF in 1952 (from ICNAF, MS 1953b). 


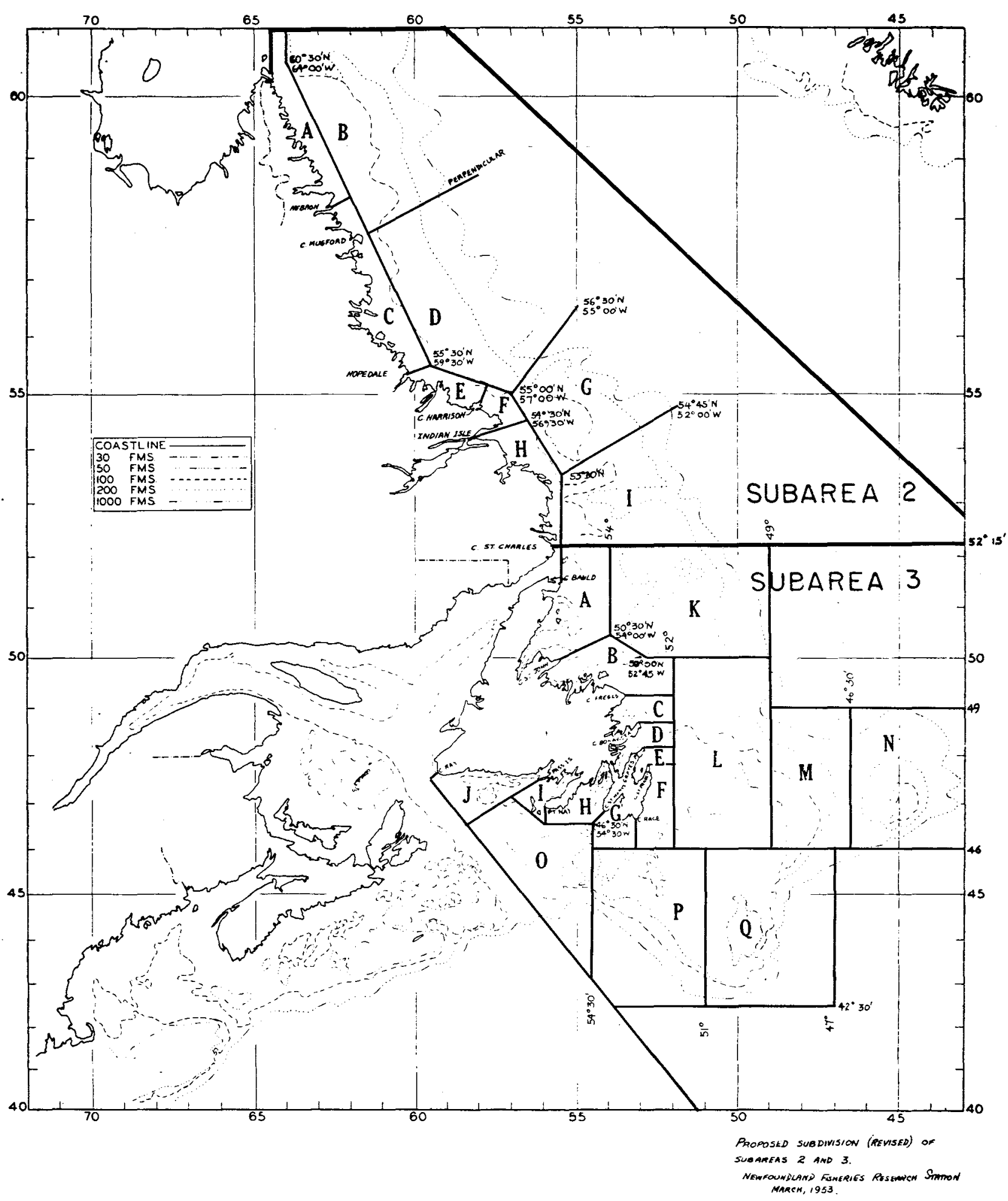

Fig. 11. Revised statistical subdivisions of Subareas 2 and 3 proposed by the Newfoundland Fisheries Research Station in 1953 (from Templeman and Fleming, MS 1953). 
3. Simplified proposal to provide for prompt submission of complete statistics on landings and fishing effort to the Commission.

4. Conformity with existing statistical unit areas and fishery-officers districts.

5. Avoidance of duplication of letters assigned to subdivisions."

The term "Division" was adopted in 1960 for the fishing areas defined by the first level of subdivision of Subareas (ICNAF, 1960a) as a result of recommendations for standardization by the CWP (FAO, 1962). At that time the areas created by the secondary splits of Div. 4V and Div. 3P into northern and southern parts (Fig. 12) became known as "Subdivisions". These splits, made in 1958, were recommended because tagging experiments had shown that cod stocks in the northern parts of Div. 4V and Div. 3P in winter were parts of Gulf of St. Lawrence stocks (ICNAF, 1958).

Other modifications to the original subdivisions occurred only in Subarea 5. The Commission gave the ICNAF Secretariat licence to produce detailed definitions of the subdivisions agreed to at the 1953 meeting. However, the description so provided by the Executive Secretary (Poulsen, MS 1953) introduced without explanation a new line at $70^{\circ} \mathrm{W}$ south from Cape Cod (Fig. 5) and included the area between $70^{\circ} \mathrm{W}$ and $71^{\circ} 40^{\prime} \mathrm{W}$ in Div. $5 \mathrm{Y}$ along with the inner Gulf of Maine area. This appears to have created difficulties in statistical reporting (ICNAF, 1956). The area was reincorporated with Div. $5 Z$ in 1957 (ICNAF, MS 1957).

These unexplained events obviously reflected an underlying dissatisfaction with the subdivision of Subarea 5. Further, or possibly the same, dissatisfaction was expressed by USA scientists as soon as 1958 and proposals were made to subdivide Div. $5 Z$ on the basis of haddock and cod stock structure (ICNAF, 1959a). Wise and Jensen (MS 1960) suggested that cod stocks in Subarea 5 were well divided by a line at $68^{\circ} \mathrm{W}$ and that haddock stocks were separated by the Great South Channel which is at about $69^{\circ} \mathrm{W}$. No change was made on that occasion but another USA proposal in 1967 to subdivide Div. $5 Z$ into Subdiv. $5 Z$ e and $5 Z W$ at $70^{\circ} \mathrm{W}$ was successful (ICNAF, 1967), i.e. the boundary line at $70^{\circ} \mathrm{W}$ dropped in 1957 was reinstituted (Fig. 12). The 1967 proposal was made to facilitate management of yellowtail flounder (Limanda ferruginea), for which both Georges Bank and coastal stocks were recognized, and was based mainly on a review of research vessel survey data (R. C. Hennemuth, Woods Hole, Mass., USA, pers. comm.). However the particular line chosen was questioned at the time by USSR scientists, who pointed out that it did not correspond to a separation of fishing banks, and indeed the first TAC regulations utilizing a subdivision of Div. 5Z, (which, coincidentally, was for yellowtail flounder) used $69^{\circ} \mathrm{W}$ rather than the then recently created Subdivision boundary. A review by Brown (MS 1974) of stock separation of all species in relation to the $69^{\circ} \mathrm{W}$ and $70^{\circ} \mathrm{W}$ lines concluded that it was impossible to establish a Subdivision boundary in this area which "serves all purposes for all species".

The introduction of TAC regulation in 1970 resulted in the use of Divisions for regulatory purposes. As the intention of TACs was to optimize exploitation of stocks, it was necessary to define management areas which corresponded with stock distributions. It was also necessary that these areas corresponded to statistical collection areas not only to provide historical data for stock assessment purposes (and hence definition of appropriate TAC levels) but for monitoring and control of catches in relation to TACs and allocations. Divisions, which were established originally with some reference to stock distributional areas (ICNAF, MS 1953a) and were also the smallest areas used by ICNAF for statistical collection, were the obvious basis for TAC regulation. The Division system provided flexibility for different combinations of 


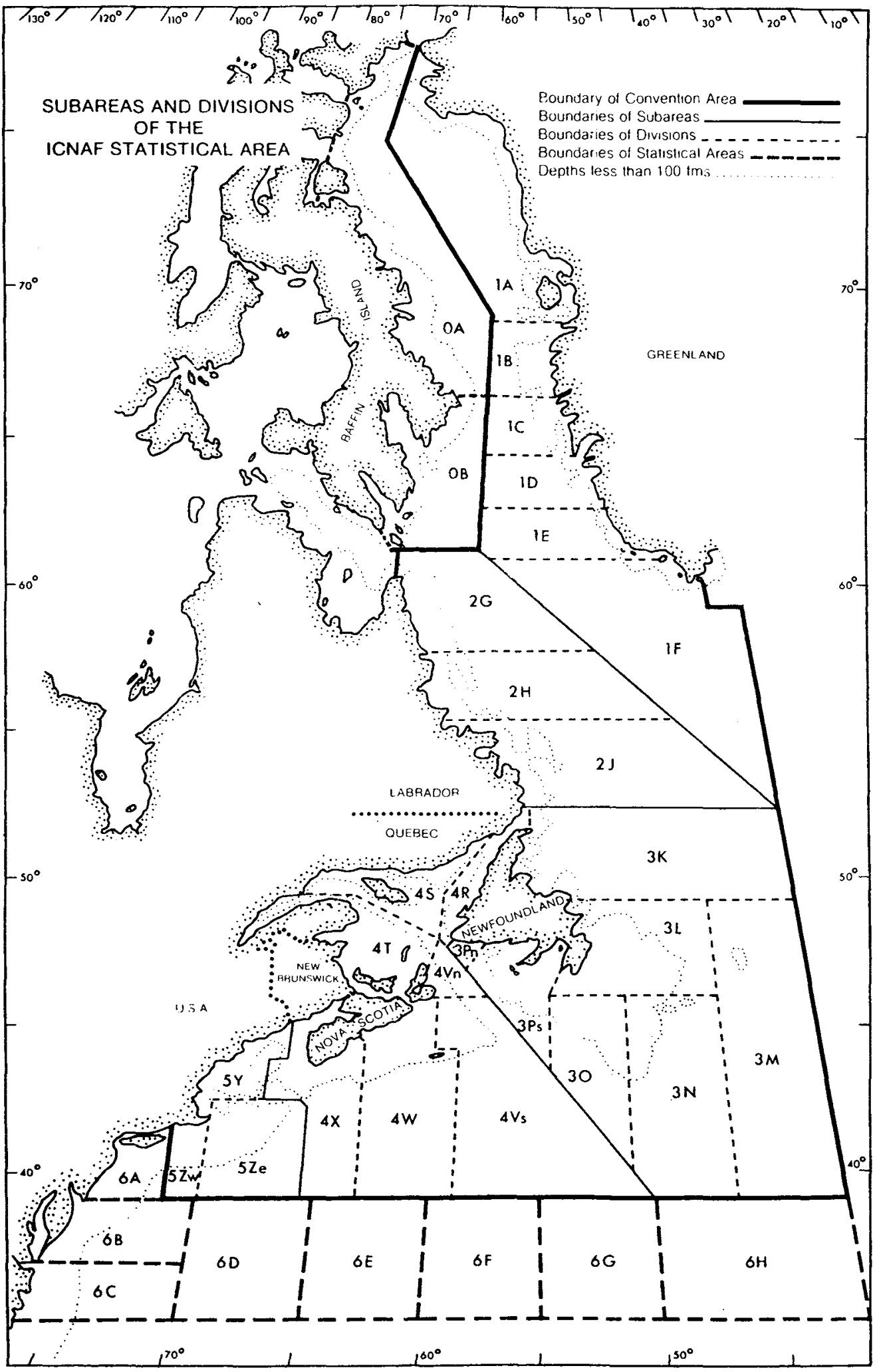

Fig. 12. Final configuration of ICNAF Subareas and Statistical Areas, and their Divisions and Subdivisions (from ICNAF, 1985 - Statistical Bulletin Vol. 28 for the year 1978 (2nd rev.), p. 12). 
Divisions to be used for stocks of different species. Combinations of time period and area also have been successfully introduced into TAC regulations. The inclusion of cod in Subdiv. $4 \mathrm{Vn}$ in the regulatory area for southern Gulf of St. Lawrence (Div. 4T) cod only during the months of January to April provides the primary example. In contrast, attempts to set TAC regulations for parts of Divisions, e.g. offshore cod in Div. $4 \mathrm{X}$ and yellowtail flounder in Div. $5 \mathrm{Z}$ east of $69^{\circ} \mathrm{W}$, created serious difficulties, as statistical systems were not in place to provide data by the regulatory areas so defined.

\section{Extensions to the ICNAF Statistical Area}

In an attempt to rationalize North Atlantic statistical areas the CWP, at its third meeting in 1963, proposed extension of the ICNAF Statistical Area south from $39^{\circ} \mathrm{N}$ to $36^{\circ} \mathrm{N}$ so that its southern boundary would be on the same latitude as the southern boundary of the ICES Statistical Area (FAO, 1963). At that time ICNAF had no interest in doing this (ICNAF, 1963) but by 1966 reports of expanding catches in the area off the USA coast south of the ICNAF Convention Area caused a reversal of views (ICNAF, 1966) and a new area was defined in 1967 between $39^{\circ} \mathrm{N}$ and $35^{\circ} \mathrm{N}$ (Fig. 12), and contiguous to Subarea 5 (ICNAF, 1967). This was labelled Statistical Area 6, although this was to an extent inconsistent as the term Statistical Area had already been adopted as referring to the whole area for which ICNAF collected statistics. However, for regulatory purposes the Commission found it easier to distinguish between a (Convention) Subarea and a Statistical Area than between two types of Subarea. Subdivisions of Statistical Area 6 were, however, referred to as Divisions.

Extension of the Statistical Area of ICNAF to any area of the Northwest Atlantic Ocean was judged to be within the authority granted under Article VI, par. 1(b) and 1(f), of the Convention. An account of the interactions between the CWP, ICNAF and USA authorities in negotiating establishment of Statistical Area 6, its boundaries and subdivisions, is provided by Gertenbach (MS 1967), but rationales for the choice of boundaries are not given. The primary motivation for creating the area was not only to provide within ICNAF a record of catches, some of which were of species (and stocks) being caught also in the Convention Area, but to provide a basis for inclusion of catch and fishing effort into scientific analyses of stock status being conducted through ICNAF, and to incorporate this area into regulations. While ICNAF could not propose regulations for areas outside of its Convention Area, it could create circumstances which facilitated bilateral and multilateral agreements between countries to take actions in the adjacent Statistical Area which were consistent with the ICNAF regulatory regime. (This did not prove to be entirely satisfactory and at one point proposals were made to include Statistical Area 6 in the Convention Area (USA, MS 1974).) The distributions of species which were fished on both sides of the western boundary of the Convention Area, particularly silver hake (Merluccius bilinearis) and red hake (Urophycis chuss) and flatfish species (ICNAF, MS 1967), were no doubt important determinants in the choice of coastal Statistical Area and Division boundaries. Extension of the area east to $42^{\circ} \mathrm{W}$ provided, more or less, the standardization with ICES areas desired by FAO. Oceanic Division boundaries were arbitrary, no significant fisheries occurring in the area. No explanation was given for the choice of $35^{\circ} \mathrm{N}$ rather than the $36^{\circ} \mathrm{N}$ which would have given uniformity with the ICES area southern limit, as was proposed in 1963 . However, $35^{\circ} \mathrm{N}$ is the closest degree of latitude to Cape Hatteras, a widely recognized faunal boundary.

Another Statistical Area was established in 1974 (ICNAF, 1974) called the Baffin Island Area and labelled Statistical Area 0 (Fig. 12). Greenland halibut (Reinhardtius hippoglossoides) and roundnose grenadier (Coryphaenoides rupestris) stocks, which were under regulation in the Convention Area, extended into the area off eastern Baffin 
Island and had been fished there since at least 1968 (ICNAF, 1975a). The northern boundary of Statistical Area 0 was defined as $66^{\circ} 15^{\prime} \mathrm{N}$ but by late 1977 it was noted that catches were being reported from north of this boundary. Information had also just become available that shrimp ( $P$ andalus borealis) stocks fished in Subarea 1 extended west into these northern waters. The boundary of Statistical Area 0 was extended, therefore, to $78^{\circ} 10^{\prime} \mathrm{N}$ (the same northern limit as Subarea 1) and the Statistical Area was divided into Div. $O A$ and $O B$ at $66^{\circ} 15^{\prime} \mathrm{N}$, Div. OA being the part added in 1978 , and Div. OB the part established in 1974 (ICNAF, 1978). This was the last modification to ICNAF fishing areas.

\section{The NAFO System}

The NAFO Convention (NAFO, 1980) which came into force on 1 January 1979 established a Convention Area identical to the Statistical Area of ICNAF (Fig. 12), i.e. it included territorial waters of coastal states as well as ICNAF Statistical Areas 0 and 6 , the latter becoming Subareas 0 and 6 in the NAFO system. ICNAF Subareas 1-5 and their Divisions and Subdivisions were incorporated unchanged into the NAFO system. The boundaries of the scientific and statistical Subareas, Divisions and Subdivisions are set out in Annex III of the NAFO Convention.

The NAFO Subareas, Divisions and Subdivisions are ostensibly for scientific and statistical purposes and can be modified by the General Council of NAFO on the request of the Scientific Council (Article XX). The NAFO Convention also establishes a Regulatory Area as that part of the Convention Area outside coastal state jurisdiction and it is only in this area that the Fisheries Commission of NAFO has authority to adopt proposals for regulatory actions by Contracting Parties. The Fisheries Commission, having consulted the Scientific Council, also has authority to propose to the General Council the division of the Regulatory Area into appropriate "regulatory" divisions and subdivisions (Article XX). None have been created. Were any to be created they would be defined in Annex III to the Convention, and hence become part of the statistical grid.

At its first Annual Meeting the NAFO General Council(NAFO, 1980) approved a Scientific Council proposal to modify the boundary between Subareas 0 and 1 (effective 1 January 1980) to coincide with the agreed boundary between Canadian and Danish fishing zones (Fig. 13). The proposal was first made to the Scientific Council by Canada apparently in recognition of the administrative and regulatory convenience of having statistical collection areas coincident with coastal state jurisdictional, and hence regulatory, boundaries. In particular, this provided a statistical basis for negotiation of allocations between coastal states of shared resources of roundnose grenadier, Greenland halibut and shrimp (Atkinson et al., 1982). The Scientific Council, in agreeing with the proposal, noted that the original boundary between Subareas 0 and 1 , in any case, had been determined arbitrarily and did not coincide with any stock boundary, and that the extent of the change (Fig. 14) was not great.

Subsequent to the decision of the International Court of Justice (ICJ) in October 1984 on the maritime boundary between Canada and the USA in the Gulf of Maine Area, Canada made proposals for a change in the boundary between NAFO Subareas 4 and 5 to make it coincide with the ICJ line (Canada, MS 1985, MS 1986). The Scientific Council agreed that it was essential that statistics be collected and recorded for the regulatory areas created by definition of the jurisdictional line (NAFO, 1985). The impact of changes on historical data series was analyzed (Halliday et al., 1986) in accordance with CWP guidelines (FAO, 1984). As a result the Scientific Council proposed that the Subarea $4 / 5$ boundary between Div. $4 X$ and Div. $5 Y$ be replaced by the ICJ line and that new fishing areas be defined on either side of the ICJ line in 


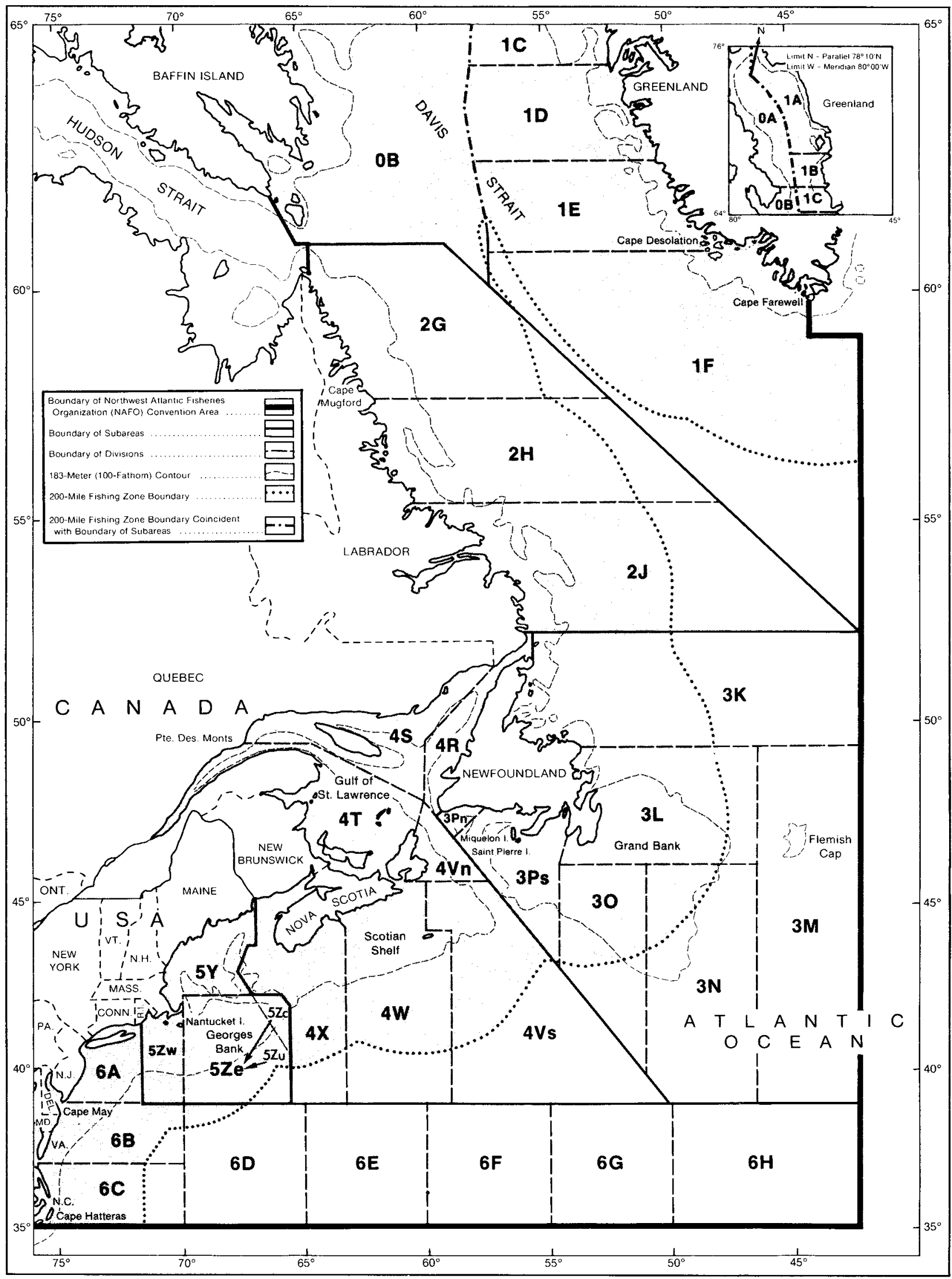

Fig. 13. NAFO Subareas, Divisions, Subdivisions and statistical reporting areas as of 9 October 1987 (from NAFO, 1989). 


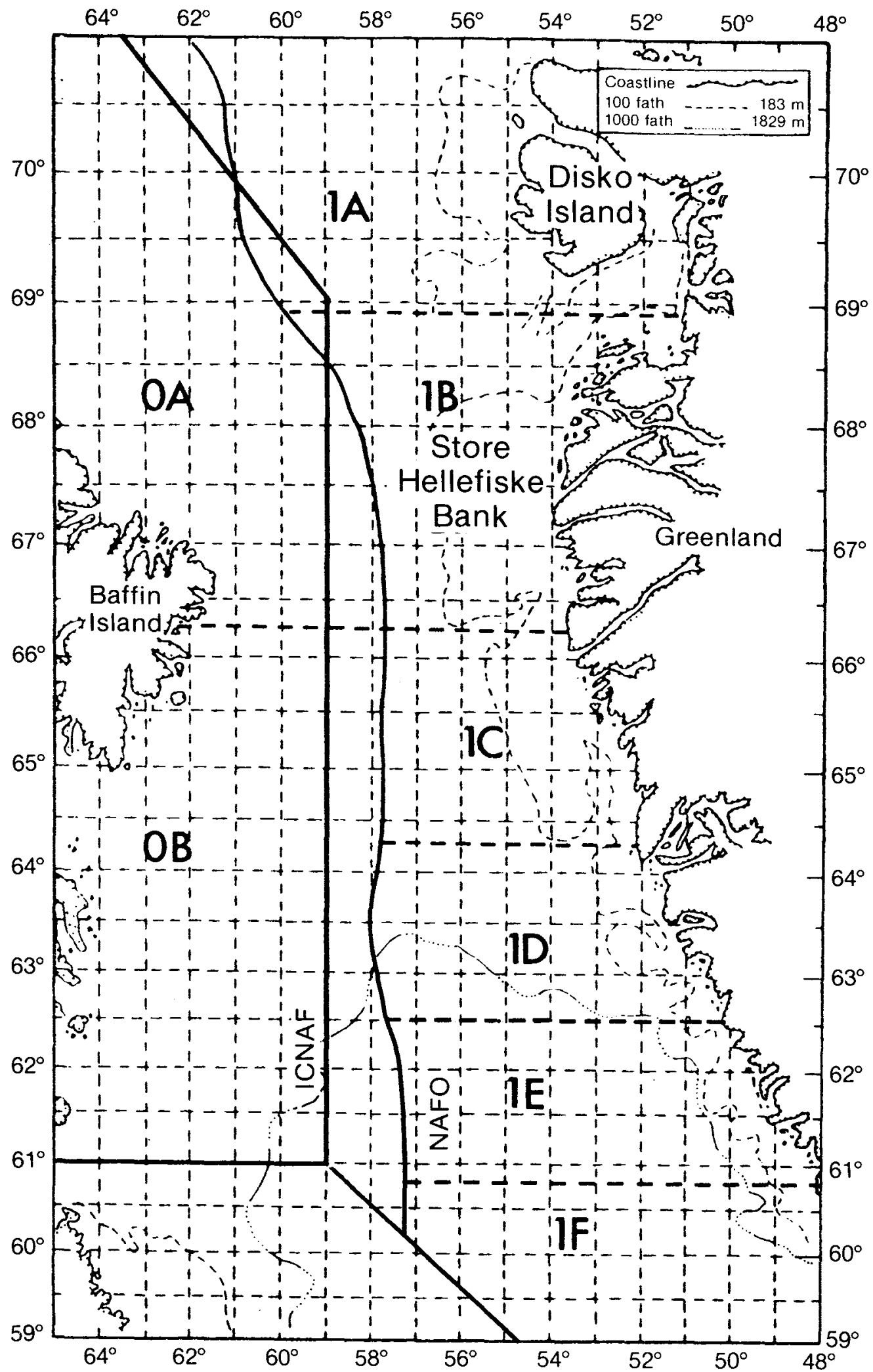

Fig. 14. Revised boundary between Subareas 0 and 1 effective 1 January 1980 (labelled NAFO) and previous boundary (labelled ICNAF), modified from Atkinson et al. (1982), figure 1. 
Subdiv. 5Ze to maintain continuity of data series for the Georges Bank area (Fig. 15). There were outstanding jurisdictional disagreements between Canada and the USA in the areas landward and seaward of the ICJ line and this necessitated that the resolution of the practical issue of statistics collection be non-prejudicial to jurisdictional claims of either party. The General Council resolved this issue (NAFO, MS 1986) by modifying the boundary between Subarea 4 and 5 between $42^{\circ} 20^{\prime} \mathrm{N}$ and $43^{\circ} 50^{\prime} \mathrm{N}$ only (effective 9 October 1987) and by simply agreeing to record and report to NAFO catches in Subdiv. 5Ze separately by Canadian and USA parts. The USA, although not a member of NAFO, agreed to cooperate with this action.

The NAFO Scientific Council (NAFO, 1986a, 1989) established two new areas, Subdiv. $5 Z c$ and $5 Z u$ (to designate Canadian and USA waters respectively) to replace Subdiv. $5 Z$ e for statistical reporting and publication purposes (Fig. 13). Thus, a de facto change in statistical areas was effected without modification to Annex III of the Convention.

Changes to NAFO fishing area boundaries have in each case reflected the desire of coastal states to rationalize statistical collection activities with newly defined jurisdictional areas. This recognizes that effective monitoring of the results of regulatory actions is an integral ingredient for successful fishery management. It can be seen as incongruous, therefore, that the boundary between coastal state jurisdictions and the Regulatory Area has not also been recognized for statistical collection purposes, particularly in Subarea 3 which is the focus for Regulatory Area fisheries. The need for this was initially avoided by agreement between Canada and the NAFO Fisheries Commission to continue using management areas previously established by ICNAF (on the basis of ICNAF Divisions), and to cooperate in the management of the numerous transboundary stocks so created (as indeed there is an obligation to do under Article XI of the Convention). However, there are differences in fishing practices and conditions in the adjacent jurisdictional areas and the lack of separate statistics prevents these being taken into account in fishery analysis and limits future options for innovative regulation.

\section{Statistical Units Smaller than Divisions}

Development of the USA fine-scale geographical "subarea" system for recording catch and fishing effort statistics by fishing grounds is well documented by Rounsefell (1948) from its initiation in 1931 through several revisions until that of 1943 (Fig. 6). Subsequent to the delimitation of ICNAF Statistical Area 6 in 1967, the USA extended this system south (Fig. 16) to include this area (ICNAF, MS 1972). Fishing effort and location data for a portion of the fleet (primarily large otter trawlers) were and still are collected, through port interviews of fishing captains, to a resolution of $10^{\prime} \times 10^{\prime}$ rectangles of latitude and longitude. These 10' $\times 10^{\prime}$ ' rectangles are referred to as 'unit areas". Interview data are then combined with data for non-interviewed vessels, obtained from purchase slips, on the basis of "subareas" (now referred to as "statistical areas" in the USA).

Canadian scientists also adopted the "subarea" system, providing input to its development for the Scotian Shelf (Rounsefell, 1948) and extending it to the Gulf of St. Lawrence (Fig. 7) in 1947 (ICNAF, MS 1952a) and to the Grand Bank-Labrador area in the 1950s. On the Grand Banks and off Labrador a grid of $30^{\prime}$ latitude by $1^{\circ}$ longitude was adopted initially (ICNAF, MS 1960). However, in the mid- to late-1960s a system of larger, irregularly shaped units (Fig. 17), similar to those in more southern areas, was adopted (ICNAF, MS 1972). The actual dates of adoption (except in the case of the Gulf of St. Lawrence) and rationales for these are not recorded. In the mid-1950s Canadian 


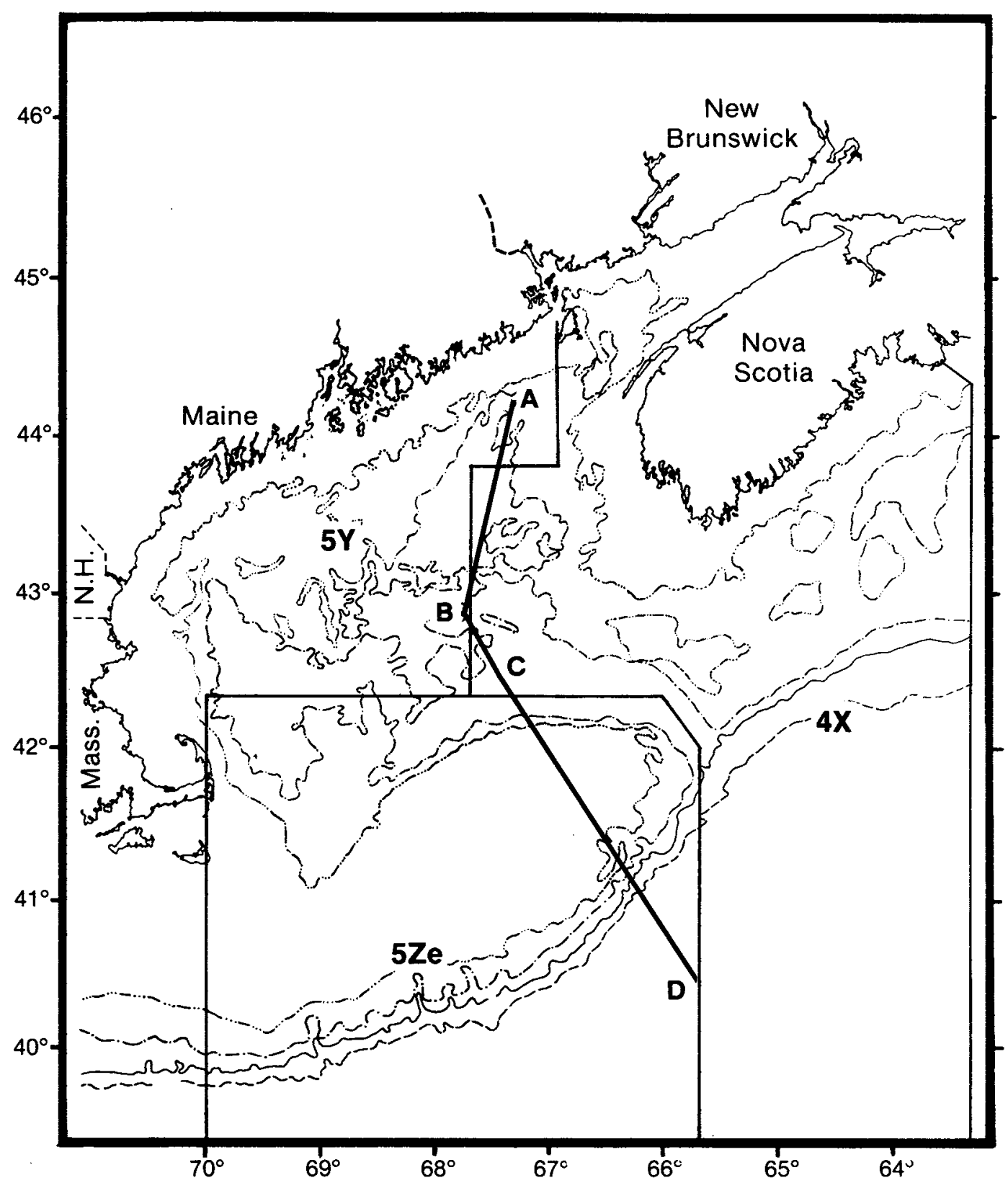

Fig. 15. The International Court of Justice (ICJ) line in relation to NAFO boundaries in the Gulf of Maine Area. That part of the ICJ line south of $42^{\circ} 20^{\prime} \mathrm{N}$ was used to divide two statistical reporting areas within Subdiv. $5 \mathrm{Ze}$, the segment between $42^{\circ} 20^{\prime} \mathrm{N}$ and $43^{\circ} 50^{\prime} \mathrm{N}$ replaced the southern part of the existing Div. $4 X / 5 Y$ boundary by modification of Annex III to the Convention, whereas that part between $43^{\circ} 50^{\prime} \mathrm{N}$ and Point $A$ was not incorporated into the NAFO system. (From Halliday et al., 1986.) 


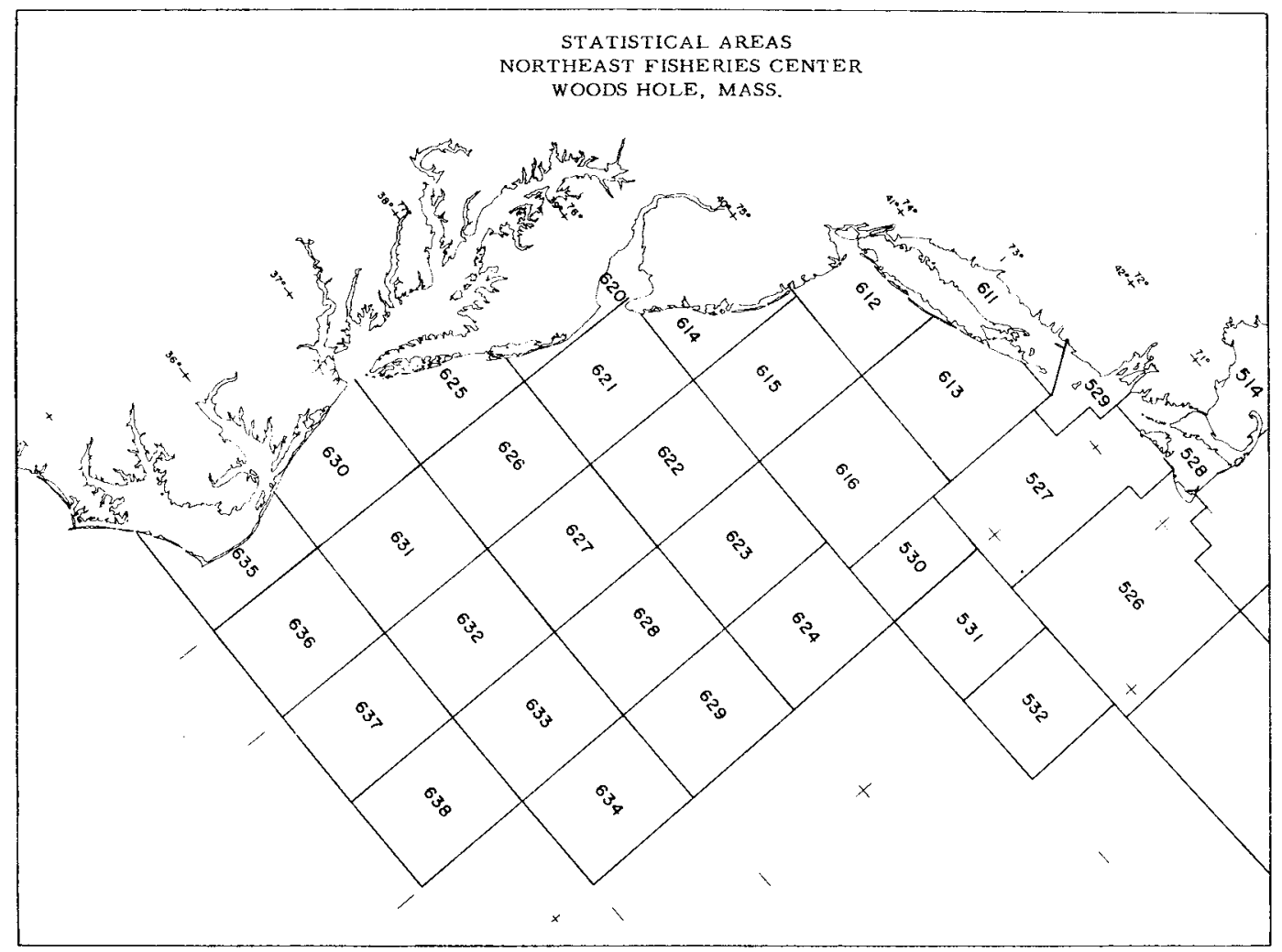

Fig. 16. Statistical "subareas" adopted by the USA for Statistical Area 6 subsequent to adoption of the latter by ICNAF in 1967 (from ICNAF, MS 1972).

scientists began referring to these as "unit areas" (the USA term for the smaller $10^{\prime} \times 10^{\prime}$ rectangles which were not used by Canada) (Sullivan and Martin, 1955) no doubt to avoid terminological confusion with the newly instituted Subareas of ICNAF. Canadian usage of these "subareas" was variable and in the Maritimes Region (the Canadian mainland Provinces of Nova Scotia, New Brunswick and Prince Edward Island), their primary use was for research purposes. However, in the Newfoundland Region (the Canadian Province of Newfoundland and Labrador) catch and fishing effort data, for that part of the commercial fleet which maintained fishing logbooks, were recorded in the regional statistical system at the "subarea" level.

In 1953 ICNAF was faced with a major decision on delimitation of fishing areas as the basis for a comprehensive recording and reporting system for international fisheries statistics. The importance of the word "comprehensive" must be appreciated to understand the difficulties faced by Contracting Parties. The requirement to be imposed was that all data for their fleets were to be collected and reported on this scale. Practical considerations dictated that these areas be larger than those already defined for Subareas 4 and 5 by Canada and the USA. It was decided that these ICNAF Divisions should be of such a size as to provide, among other things, areas homogeneous with respect to stock composition, in contrast to the smaller areas which were intended to define areas homogeneous with respect to fish density or, at least, to delimit areas of persistent concentrations of particular fish species as reflected in fishery distributions.

There was, however, recurring dissatisfaction with this decision. It was reviewed in 1959-60 and 1963-64. On both occasions the CWP recommended adoption of a 


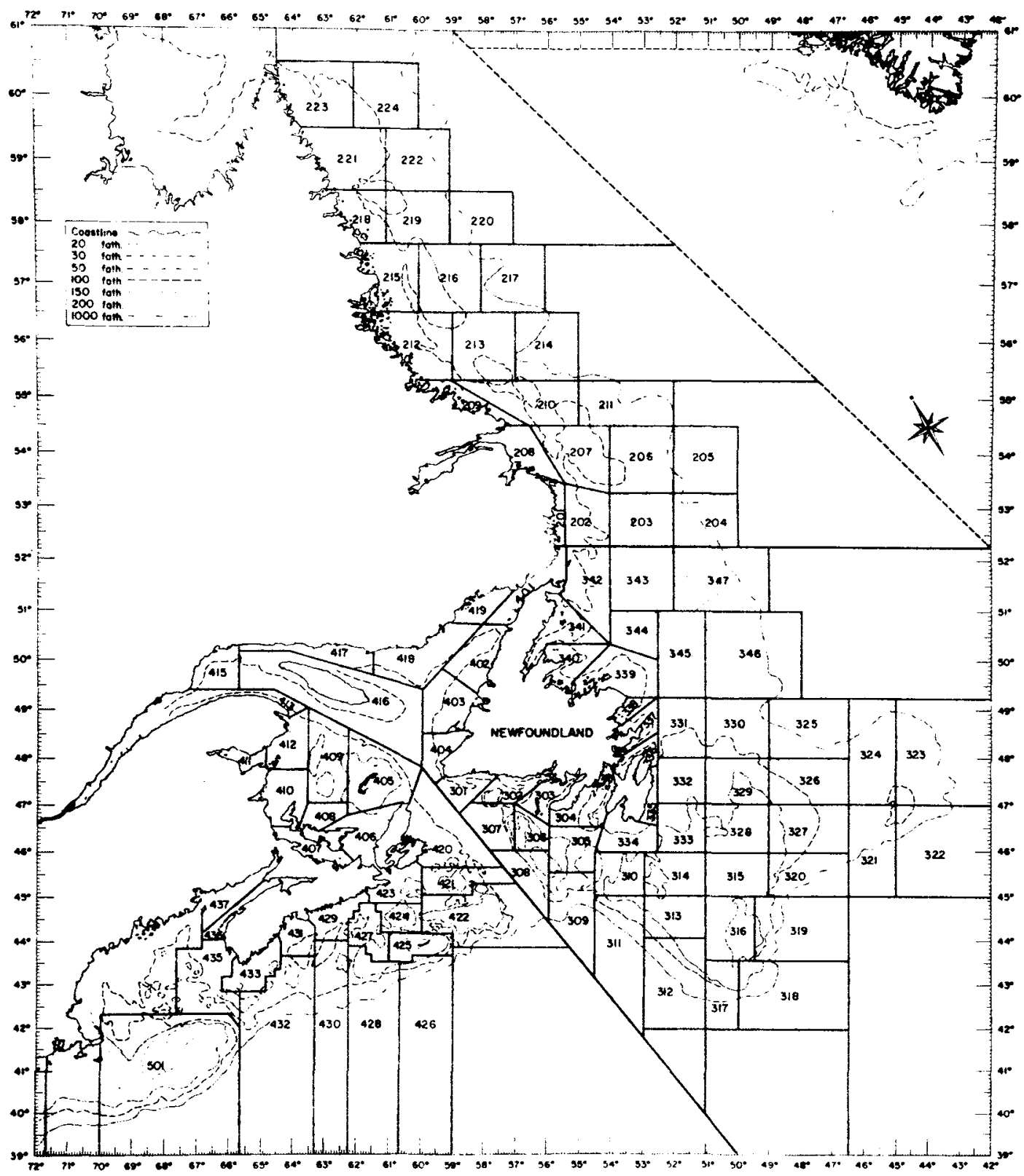

Fig. 17. Statistical "subareas" in use by Canada in 1972 for ICNAF Subareas 2-4 (from ICNAF, MS 1972). Those for Subareas 2 and 3 were adopted in the mid- to late-1960s.

system of statistical rectangles, i.e. a graticule system (FAO, 1962, MS 1964). National "subarea" systems were also reviewed (DeBaie, MS 1964, ICNAF, MS 1960). While STACRES was prepared to agree that "the smallest practicable unit area should be used for collection of statistics" (ICNAF, 1959b), it was not able to decide upon the most desirable size and form of these units (ICNAF, 1960b). Finally STACRES decided not to propose a reporting requirement by areas smaller than Divisions (ICNAF, 1964). Clearly, the practical difficulties of obtaining comprehensive reporting of data on a fine geographical scale again outweighed its scientific desirability.

The most intensive study of reporting areas was stimulated by the introduction of TAC regulations by ICNAF in the early-1970s. These regulations were expected to 
disrupt the long-established fishing patterns on which the usefulness of catch and fishing effort data for abundance estimation depended. Thus the value of the data for scientific stock assessments was in danger of being negated by utilization of the assessment results in regulation. The solution to this problem was seen to be the use of smaller areas for statistical reporting (ICNAF, 1971) and in 1972 STACRES recommended "that member countries initiate plans for the introduction of more detailed and flexible statistical reporting systems" (ICNAF, 1972b). The limitations of ICNAF statistical data for support of the 1970 s regulatory aspirations quickly became a contentious issue (e.g.USA, MS 1973) and STACRES established a Special Working Group on Data Base Improvement in 1973 (ICNAF, 1973). As part of its overall recommendations this working group proposed collection of statistics by $30^{\prime} \times 30^{\prime}$ rectangles and twicemonthly time periods (ICNAF, 1974). It was explained that this finer breakdown of catch and effort data would aid in the assessment of the mixed fishery problem, assist in the assessment of species with geographical ranges which did not correspond with current reporting areas, and help to refine measures of fishing effort (for effort regulation). The Working Group provided a variety of examples of fisheries for which more detailed data would have allowed for "a desirable degree of improvement in the accuracy of assessments and monitoring" but admitted that the scale of data collection recommended was a matter of scientific judgement rather than being based on analytical demonstration of resulting benefits. The USA proposed (USA, MS 1975), and the ICNAF Commission approved (ICNAF, 1975b), collection of statistics as recommended by the Working Group starting with 1976 statistics which were due to be reported in 1977. Many of the steps necessary to effect this change were implemented but extensions of coastal state jurisdictions in 1977 resulted in a reappraisal, and STACRES proposed a delay in implementation to avoid possible duplication in reporting requirements with those of coastal states (ICNAF, 1977). This deferral of plans for a standard regional system was not reviewed by STACRES, nor has the NAFO Scientific Council considered needs for finer scale data for Regulatory Area fisheries.

Coastal states did implement reporting requirements on a geographical scale smaller than Division. The USA, which had maintained domestic records of area of capture on the basis of a 10' graticule for a portion of its fleet based on port interviews of fishing captains and comprehensively by "subareas" ("statistical areas" in USA parlance), in addition introduced a system in the mid-1970s which comprehensively attributed records on the basis of a 30' graticule. Although the ICNAF requirement for these data was deferred, the system was maintained and is still in use (Burns and Schultz, MS 1989). Canada, which had comprehensively recorded domestic commercial fishery data on a Division basis only, adopted the long-established "subarea" system as the basic geographical unit for comprehensive commercial statistics recording at the time of extension of jurisdiction. At that time the "subareas" used ("unit areas" in Canadian parlance) were described fully by geographical coordinates (Jones, MS 1978). In the late-1980s most fisheries administrative regions in Atlantic Canada also began recording each haul of large groundfish trawlers in their statistical systems on a smaller scale than "subarea" - either by precise latitude and longitude or by $10^{\prime}$ graticule. Greenland has, since 1976, recorded area of capture data for domestic large vessels on the basis of a graticule of $7.5^{\prime}$ latitude by $15^{\prime}$ longitude. All smaller vessels were included in this system (to the extent possible) from $1984(\mathrm{H}$. Lassen, Greenland Fisheries Research Institute, Copenhagen, Denmark, pers. comm.). On extensions of jurisdiction coastal states did indeed also place additional reporting requirements on foreign vessels fishing in their zones. The USA required submission of data by $30^{\prime} \times 30^{\prime}$ rectangles and Canada required copies of original log books. However, these demands were not lasting and both countries gradually moved to essentially $100 \%$ observer coverage. In the case of Canada, observer data are captured 
in computerized data files by the latitude and longitude of each haul. Thus, subsequent to extensions of jurisdiction, there have been extensive efforts to obtain fishery data on a fine geographical scale. However, a number of different scales have come into use, some for comprehensive application and others for particular fleets.

\section{Availability of Scientific Knowledge}

There is remarkably little documentation of the scientific knowledge which was actually utilized in decision making about the precise locations of specific statistical boundary lines. The historical record does provide accounts of the general principles used in boundary delineation. The NACFI lines were chosen "to correspond as far as possible with natural divisions of the fish populations or with barriers to fish migrations" (Found, 1933). Barriers to migrations presumably were of topographic or oceanographic nature. Côté (MS 1953) explicitly listed topography, oceanography and stock structure (in that order) as the "ideal" bases for subdivision of ICNAF Subareas although, of these, ICNAF (MS 1953a) emphasized stock structure only (along with uniformity of size of subdivisions, ease of use and conformity with existing divisions). Faunal composition, or at least the distribution of commercial species, (i.e. zoogeography) also influenced some boundary decisions.

With regard to oceanography, a cooperative research programme on water circulation in the Northwest Atlantic was initiated by NACFI in 1922 and by 1932, when NACFI first divided the Atlantic into fishing areas, charts of surface circulation in the area from Labrador to Nantucket Shoals were available (Bigelow, 1928; NACFI, 1932). By 1953, when the ICNAF system of Divisions was established, quite a comprehensive general description of the waters of the ICNAF Convention Area was possible (Hachey et al., 1954). While this broadscale knowledge of circulation and fronts likely influenced views to some degree, the fact remains that there is no evidence in the historical record of a specific case where oceanographic information was used explicitly in decision making about a northwest Atlantic statistical boundary.

Views on zoogeographic boundaries in the Northwest Atlantic have been fairly consistent from their first development in the mid-1800s (Hazel, 1970). Most often boundaries are recognized between Arctic and Nova Scotian provinces at Cape Race, Newfoundland $\left(47^{\circ} \mathrm{N}\right)$, between Nova Scotian and Virginian provinces at Cape Cod $\left(42^{\circ} \mathrm{N}\right)$ and between Virginian and Carolinian provinces at Cape Hatteras $\left(35^{\circ} \mathrm{N}\right)$. Scientists within NACFI were no doubt aware of these views in 1932 but clearly paid no attention to the idea of a boundary at about $47^{\circ} \mathrm{N}$. This is understandable in a fishery context as the fishery distribution of the dominant species, cod, showed no discontinuity in that area. The southern limit of the large scale commercial fishery for haddock in the area of Nantucket Shoals, south of Cape Cod (Rounsefell, 1948) appears to have been the rationale for division of New England and Middle Atlantic regions at $71^{\circ} 45^{\prime} \mathrm{W}$ (Fig. 3). This could be viewed as de facto recognition of a faunal boundary at Cape Cod. At least, the NACFI division between Middle Atlantic States and South Atlantic States regions at $36^{\circ} 33^{\prime} \mathrm{N}$ (Fig. 3) was quite likely a recognition of Cape Hatteras as a faunal boundary. The exact latitude chosen, the boundary between the states of Virginia and North Carolina, perhaps reflected compromise for convenience in collection of fishery statistics. The ICNAF choice of $35^{\circ} \mathrm{N}$ as the southern boundary for Statistical Area 6 may also have been a recognition of the ecological significance of Cape Hatteras. Thus, while zoogeographic concepts appear to have had some influence they did not weigh heavily in statistical boundary decisions. 
It is clear, then, that the primary scientific input to fishing area delimitation was information on stock structure. As already noted, the historical record contains little reference to exactly what knowledge was applied in determination of specific boundaries. This can only be referred by examination of the knowledge base available at the times decisions were made. Therefore, the state of knowledge about stock separation is reviewed at each of the key decision-making periods. The key times were 1932 when NACFI chose its regional boundaries, 1953 when ICNAF determined its divisional boundaries and 1958-62 when the latter were thoroughly reviewed by STACRES. A review of present knowledge concerning stock structure is also necessary to determine whether, after a further 30 years of research, these early determinations of statistical boundaries still appear to provide reasonable approximations of major stock boundaries and thus provide a suitable basis for resource management today.

\section{In 1932}

The NACFI statistical areas agreed to in 1932 have had a lasting influence on regional statistics collection but the knowledge of stock structure, on which they were allegedly based, was limited. Research on marine fisheries in the 1920 s centred almost exclusively on cod, haddock and mackerel (Scomber scombrus) (NACFI, 1932, 1935). Clearly, Needler's (1930) conclusion that Northwest Atlantic haddock were divided into three groups by the deep Laurentian and Fundian channels was strongly influential in the placement of statistical boundaries in these channels between area $X X$ (Grand Banks Region) and area XXI (Nova Scotia Region), and between area XXI and area XXII (New England Region) respectively (Fig. 3). Needler's paper may have been the source of the term, regions, used by NACFI to refer to its fishing areas. Needler's conclusions were based on tagging experiments and analysis of age composition and growth rates which indicated practically no interchange between Nova Scotia and New England regions. His conclusions on the lack of interchange across the Laurentian Channel was an inference based largely on channel depth, supported by a lack of tag returns from east of the channel. As already mentioned, the boundary between areas XXII and XXIII off southern New England represented the western limit of the haddock fishery (Rounsefell, 1948).

Greenland and Newfoundland areas were included in the ICES statistical system in 1925 and 1926 respectively but these statistical areas had no specified boundaries (ICES, MS 1982). An ICES chart, fully defining its statistical boundaries was produced in 1932, coincident with the NACFI chart for the Northwest Atlantic. Both charts showed East and West Greenland as separate areas XIV and XV (Fig. 3). By this time tagging experiments had clearly established that cod at West Greenland had close associations with those at East Greenland and at Iceland but that there was negligible association with those at Labrador and at Newfoundland to the west (Schmidt, 1931). Almost certainly, the boundaries defining West Greenland were arbitrarily chosen through deep water areas separating the Greenland banks from Baffin Island and Labrador.

There is no evidence that the Labrador and eastern Newfoundland dividing lines were based on biological data. The positioning of the lines suggests a geographical basis, area XVII being the Atlantic coast of Labrador, area XVIII being the east coast of Newfoundland and area XX being the Grand Banks (Fig. 3). Thompson's (1943) work on cod stocks in these areas began in 1931, the year the NACFI chart was first drawn up, and his first results were available in 1932, the year the chart was finalized. Interestingly, these first results suggested a stock division off eastern Newfoundland in broadly the same location in which the statistical lines had been drawn (NACFI, 1935) but it would seem that the results were not sufficient cause for Thompson to 
propose last-minute changes to the precise locations of the lines. The positioning of the line between areas XIX (Gulf of St. Lawrence) and XX (Grand Banks) was, however, influenced by Thompson. The NACFI 1931 draft proposal separated the Gulf of St. Lawrence from the offshore banks by a line from Scatarie Island, off eastern Cape Breton Island, to Hermitage Bay, approximately midway along the south coast of Newfoundland (Fig. 2). In the face of a proposed Canadian revision which would have placed the line from Cape St. Lawrence, the northern-most tip of Cape Breton Island, to Cape Anguille, the western-most tip of Newfoundland, Thompson insisted ${ }^{8}$ on retaining the line through Hermitage Bay. Presumably this reflected his results on cod stock separation, based on numbers of first year sclerites in scales, which showed that the distribution of Gulf of St. Lawrence cod extended along the south coast of Newfoundland. The Canadian view that Sydney Bight should be associated with the Scotian Shelf rather than the Gulf of St. Lawrence was presumably influenced by McKenzie's (1934) cod tagging results which demonstrated that Sydney Bight cod migrated to offshore banks west of the Laurentian Channel in winter. Accommodation of these views resulted in the sawtooth boundary incorporated in the final 1932 chart (Fig. 3).

Off Nova Scotia and New England, cod tagging conducted in the 1920s and early-1930s indicated that coastal cod off southwestern Nova Scotia and Maine were largely sedentary, an observation not inconsistent with adoption of a Fundian Channel dividing line between Nova Scotia and New England regions (Schroeder, 1930; NACFI, 1932; McKenzie, 1934; Wise, 1963). Few fish tagged off Nova Scotia crossed the Laurentian Channel, which was evidence supportive of a Laurentian Channel dividing line between Nova Scotia and Grand Banks regions.

In summary, distribution of the cod and haddock fisheries, which were of overriding importance, dominated scientific thinking and oriented it towards fisheries on the banks and the separation of these by lines through channels. The $1932 \mathrm{NACFI}$ statistical areas benefited from the first results of research on haddock and cod stock structure but a number of the regions appear to have been defined largely on the basis of geography, in the absence of biological information.

\section{In 1953}

Rather more was known about stock structure of cod and haddock, but little about other species, when ICNAF Divisions were delineated in 1953. Available biological knowledge was summarized by Martin (1953) and Templeman (1953).

The association of West Greenland cod with more eastern stocks was well established by tagging experiments (Hansen, 1949; Tåning, 1937). Three major stock groupings were recognized off Newfoundland and Labrador based on vertebral counts, tagging, biological parameters and parasites: one comprising cod off Labrador, the east coast of Newfoundland and on the northern edge of the Grand Bank; one on the southern and central Grand Bank; and one off the west coast of Newfoundland which overwintered along the western south coast as far south as Burgeo Bank and east to Hermitage Bay. The relationships of St. Pierre Bank cod were not clear, but the Laurentian and Fundian channels were confirmed as important barriers to the movement of cod. Three coastal groups and an offshore group were recognized off the Atlantic coast of Nova Scotia. Three groups in the southern Gulf of St. Lawrence and a northern Gulf group were also identified. The seasonal migration out of the southern Gulf to Sydney Bight and south along the western edge of the Laurentian Channel was not recognized by Martin, however, despite Templeman's identification of this possibility 2 years earlier (Templeman, MS 1952). The conclusions were based mainly on

\footnotetext{
7 Correspondence files, Canadian Government archives.
} 
the results of Thompson (1943), the tagging and vertebral count work subsequently published by McKenzie (1956) and McKenzie and Smith (1955) respectively, and provisional results of work initiated after the hiatus of the Second World War.

Grand Bank and St. Pierre Bank haddock were considered to be of separate stocks based on persistent differences in growth rates and year-class compositions, and a very small Flemish Cap stock was recognized on the same basis. A small west coastsouthwest coast of Newfoundland stock was identified based on vertebral count differences. The clear-cut distinction between haddock on either side of the Laurentian and Fundian channels was emphasized, but seven stocks were recognized in the Nova Scotia region. A distinction was made, however, between western and eastern populations, western populations migrating less extensively, growing more slowly, weighing more at length, having a different year-class composition and lower vertebral count. Thompson (1939) had strengthened Needier's (1930) conclusions about the importance of the Laurentian Channel as a migration barrier through a study of the comparative biology of Grand Bank and Scotian Shelf haddock. Schuck and Arnold (1951) confirmed the importance of the Fundian Channel as a barrier based on a comparison of growth rates and age compositions of Browns Bank and Georges Bank haddock, and Schroeder (1942) reported results of tagging in USA coastal waters which showed no movement to the Nova Scotia region. Evidence based on vertebral counts (Vladykov, 1935) both confirmed these major separations and provided details of the complex structure of Nova Scotian stocks suspected earlier by Needler (1930). Unpublished information was also accumulating from post-war research activities.

Some information was also available for redifsh (Sebastes spp.), American plaice (Hippoglossoides platessoides) and Atlantic halibut (Hippoglossus hippoglossus). Redfish stock structure was addressed using data on meristic variation, growth and parasites but the primary conclusion on stock structure was that redfish were fairly sedentary. Inshore and offshore stocks of American plaice in the Newfoundland area could be separated based on biological characteristics but meristic counts did not differ greatly throughout the area. It was concluded, based on McCracken's (1958) tagging work in 1945-47, that Atlantic halibut were also confined by the Laurentian and Fundian channels and that there were a number of separate populations within the Nova Scotia and Gulf of St. Lawrence regions.

Much of this information was available in 1949 when the ICNAF Subareas were being decided upon and the choice of Fundian Channel and Laurentian Channel Subarea boundaries were consistent with it. However, the choice of a northern terminus to the Laurentian Channel boundary between Subareas 3 and 4 at Cape Ray on the extreme southwest of Newfoundland (Fig. 2), rather than NACFI's Hermitage Bay line, ignored the available information on cod stocks. (The Cape Ray boundary appears to be an adoption of that between "subareas" $D$ and E described by Canada for the Gulf of St. Lawrence in 1947 - Fig. 7.) Similarly, the association of the NACFI East Coast of Newfoundland Region (area XVIII) with the Grand Banks (area XX) rather than with Labrador (area XVII), and initial proposals to associate Labrador with Greenland (corrected at Danish insistence), were not consistent with knowledge of cod stock separation. This confirms that views on national fisheries distributions, and anticipated consequential political composition of Panels, weighed most heavily in definition of Subareas.

The 1953 Divisions for Subarea 1 (West Greenland) corresponded, with some amalgamation, to Greenlandic administrative districts (Fig. 8) but also separated quite well the major offshore banks on which the cod fishery was conducted. There was little 
cod fishing north of Disko Bay in southern Div. 1A. Store Hellefiske and Lille Hellefiske banks were contained within Div. 1B and 1C respectively and Fylla, Fiskanaes and Dana banks were encompassed by Div. 1D. It had been shown that more northern groups of cod had progressively less association with Iceland, therefore this subdivision was suitable for analysis of cod populations. Thus, the Division boundaries chosen probably reflected current thoughts on stock separation (Sv. Aa. Horsted, Greenland Fisheries Research Institute, Copenhagen, Denmark, pers. comm.) with some element of administrative convenience.

Subarea 2 Divisions were proposed initially by Newfoundland scientists in conformity "with knowledge of groundfish populations and distribution of fishing effort" (ICNAF, MS 1952a) and reflected Templeman's (1953) view, based on a cline in growth rates within the Labrador-East Newfoundland cod stock, that complete mixing throughout its area of distribution does not occur. Thus subgrouping of data would be useful in population analyses. The 1952 proposal, comprising five inshore and four offshore divisions, was tentatively adopted (Fig. 9). Templeman and Fleming (MS 1953) made virtually the same proposal to the decisive 1953 ICNAF meeting (Fig. 11). In contrast, the ICNAF choice in 1953 was to adopt only three divisions (Fig. 5), divided by parallels of latitude (rather than lines drawn more or less perpendicular to the coast as originally proposed). The practicality of an arbitrary solution appears to have weighed heavily.

The 1952 proposal made by Newfoundland scientists (Fig. 9) also proposed to divide Subarea 3 into 10 inshore and 17 offshore divisions (ICNAF, MS 1952a). However, STACRES preferred a grid system for the offshore area (Fig. 10) on a scale of $4^{\circ}$ longitude and $2^{\circ}$ latitude (ICNAF, MS 1952b) which simplified boundaries, but retained about the same number of divisions. Templeman and Fleming (MS 1953) made a substantially revised proposal to the 1953 meeting which reduced the number of offshore divisions to 7 (Fig. 11). This proposal emphasized the need for a single division incorporating all of St. Pierre Bank but separate from Grand Bank, division of southern Grand Bank into eastern and western sections, and separation of Flemish Cap from Grand Bank through the deep channel between them. These are all features which were included in ICNAF's final scheme (Fig. 5). However, ICNAF's scheme dispensed with the numerous inshore areas and placed all of the northern Grand Bank into one division (Div. 3L), thus reducing the total number of areas to 6 .

There clearly were conflicting opinions with regard to the optimal division of Subarea 3. The separation of Flemish Cap no doubt seemed worthwhile based on geography alone and in addition a small haddock stock had been associated with the bank. Although Templeman (1953) was uncertain about the stock discreteness of St. Pierre Bank cod, in the case of haddock he was unequivocal about separation of St. Pierre Bank and Grand Bank stocks, justifying the boundary between these banks. The division of the Grand Bank into eastern and western parts was based on fishery distributions rather than stock information (Templeman and Fleming, MS 1953), the southern and central Grand Bank cod being considered to form a single stock. It is particularly surprising, however, that the opportunity was not taken to locate a boundary in the Hermitage Channel, i.e. to accept Templeman and Fleming's (MS 1953) proposed area $\mathrm{J}$ (Fig. 11), despite the well-established association of western south coast cod with those off the west coast of Newfoundland, and some evidence that the same was true for haddock (Templeman, 1953). It is also impossible to determine from the published record the reason for the STACRES choice of boundaries for Div. $3 \mathrm{~L}$ and difficult to reconcile this choice with Templeman's (1953) portrayal of complex stock divisions within this area. In this case, simplicity and practicalities of data collection appear to have outweighed biological knowledge. 
In Subarea 4, Gulf of St. Lawrence Division boundaries followed the major subdivisions of the region in the "subarea" system established in 1947. These lines ran along the deep channels and subdivided the area into regions which Martin (1953) recognized as containing separate cod stocks. There was perhaps also an element of administrative convenience to the choices, the boundary between Div. 4R and $4 S$ having a northeastern terminus at the Quebec-Labrador Provincial boundary.

Martin's (1953) account of five cod and seven haddock stocks in the Nova Scotian region does not by any means make it obvious why ICNAF chose to divide the region into the three Divisions, $4 \mathrm{~V}, 4 \mathrm{~W}$ and $4 \mathrm{X}$. However, the rationale is more apparent from McKenzie's (1956) account of the 1924-40 cod tagging experiments, the results of which would also have been available to Martin. These experiments showed that Banquereau fish, which tended to migrate north to Sydney Bight and beyond in summer, were separate from Sable Island Bank fish, which in part moved to adjacent Nova Scotia coastal waters in summer. Western Nova Scotia coastal cod were relatively sedentary. Similarly, Needler (1930) had concluded that haddock found in the Sable Island Bank area in winter migrated to coastal waters and into the Gulf of St. Lawrence in summer, whereas western Scotian Shelf haddock formed a number of groups with limited migrations. There was, therefore, reasonable evidence to divide the Scotian Shelf along its deepest channels into the three Divisions chosen.

Regarding Subarea 5, Needler (1930) had also described the seasonal migration of haddock tagged in coastal waters of the Gulf of Maine and on Nantucket Shoals, and implied that there was a separation from those of Georges Bank. Schroeder (1942) largely confirmed these results (based in part on the same data). Coastal cod in the Gulf of Maine were thought to be fairly sedentary (NACFI, 1932). Cod on the Nantucket Shoals made coastal migrations to the southwest, but were fairly separate from cod to the north and east (Schroeder, 1930). This was likely sufficient justification to separate coastal parts of Subarea 5, including Nantucket Shoals, as Div. 5Y, from the more offshore South Channel and Georges Bank area (Div. 5Z), although it provides little support for Poulsen's (MS 1953) choice of $70^{\circ} \mathrm{W}$ as the division between Georges Bank and Nantucket Shoais.

In conclusion, the fisheries for cod and haddock, the most important commercial species in the ICNAF Convention Area, occurred on banks and in coastal areas and the information indicated that these tended to be separated into stocks by deep water channels between banks, although there were often close associations between fish from the banks and those in adjacent coastal areas despite intervening channels. This clearly influenced division of Subareas into separate banks, parts of banks, and groups of banks, of fairly uniform size (and may have provided a rationale for not generally separating banks from coastal shelves). It is also clear that all of the specified general principles (ICNAF, MS 1953a) were given important weight in deciding on boundaries, thus stock separation was of substantial but not over-riding importance. The influence of knowledge on stock identification of cod and haddock can be detected most clearly in the southern half of the Convention Area (Subareas 3-5) but in some cases, e.g. Hermitage Channel, available evidence appears to have been ignored. Knowledge of stock separation in species other than cod and haddock was too scant to have any significant influence.

\section{In 1958-62}

The 1958 decision to split Div. 4V and 3P into northern and southern Subdivisions was based on results from cod tagging experiments. Those conducted in the summers of 1955-58 in Div. 4T clearly illustrated that these fish overwintered along the edge of 
the Laurentian Channel in northern Div. 4V (McCracken, 1959; Martin, 1959). A tagging experiment on the west coast of Newfoundland in 1948 had also reconfirmed Thompson's (1943) results illustrating that these fish largely overwintered in northwestern Div. 3P (Templeman and Fleming, 1962). However, it was decided by STACRES to place the Div. 3P dividing line through the channel to the west of Burgeo Bank rather than through the more easterly Hermitage Channel which separates Burgeo Bank and St. Pierre Bank (Fig. 2). There is no record of why this channel was favoured.

ICNAF decided to conduct a comprehensive review of stock structure when the issue of a split in Div. $5 Z$ was raised immediately after the decision to split Div. 3P and 4V. The initial review by Wise and Jensen (MS 1960) was followed by production of stock maps for cod, haddock, redfish and Atlantic halibut (ICNAF, 1961), and the review was completed by the definitive papers on cod and haddock stock structure by Templeman (1962) and Grosslein (1962) respectively.

Templeman (1962) had the extensive work of Fleming (1960) on growth and maturity of Subarea 2 and $3 \mathrm{cod}$, the final reports of Subarea 4 vertebral count (McKenzie and Smith, 1955) and tagging (McKenzie, 1956) studies, and the tagging results of Wise (1963) in the Gulf of Maine Area, as well as the papers cited above in relation to the subdivision of Div. $3 \mathrm{P}$ and $4 \mathrm{~V}$, to draw upon. Provisional results of the 1959-62 Nova Scotia banks taggings (Martin and Jean, 1964) were probably also available to him. Relevant parasite data were published (Scott and Martin, 1957, 1959, Templeman et al., 1957; Templeman and Fleming, 1963) and unpublished data included many vertebral counts for Subareas 2 and 3 (subsequently incorporated in Templeman, 1981). (The provisional parasite results of Templeman and Fleming (1963) were subsequently incorporated in the definitive paper by Templeman et al. (1976).)

Templeman (1962) recognized northern and southern West Greenland stocks of cod and several fjord stocks, the boundary between northern and southern stocks corresponding fairly well with that between Div. 1D and 1E. Templeman did not accept Fleming's (1960) conclusion that Labrador and East Newfoundland cod should be recognized as separate stocks but continued to consider them as one while recognizing that there was likely a variety of sub-stocks within the area. He took the southern boundary of this complex as being "in the general neighbourhood of St. John's" and illustrated it in his figure 5 by the line at $47^{\circ} 00^{\prime}-47^{\circ} 30^{\prime} \mathrm{N}$, substantially north of the southern boundary of Div. $3 \mathrm{~L}$ at $46^{\circ} 00^{\prime} \mathrm{N}$. A separate Flemish Cap stock was recognized, as was a Grand Bank stock. A series of stocks was recognized off the south coast of Newfoundland on southern and northern St. Pierre Bank, on Burgeo Bank and in the coastal Avalon-Burin Peninsula area.

Templeman (1962) recognized the complex of cod stocks in Div. 4T (identifying five) which migrated out of the southern Gulf to overwinter mainly in Subdiv. $4 \mathrm{Vn}$. He also disclosed that North Shore Gulf of St. Lawrence and Anticosti stocks joined the west coast of Newfoundland stock on overwintering grounds in Div. 3P based on unpublished tagging results, subsequently reported in part by Jean (1963). Templeman's conclusions for Scotian Shelf and Gulf of Maine stocks followed closely the results of McKenzie (1956) and Wise (1963), with banks stocks being identified in association with Banquereau, Sable Island, Browns and Georges banks and a complex of coastal stocks extending from Sydney Bight to Nantucket Shoals being recognized.

Grosslein (1962) followed Templeman (1953) in recognizing Grand Bank, St. Pierre Bank, and western Newfoundland haddock stocks, but questioned the persistence of haddock on Flemish Cap. Grosslein also recognized an eastern Scotian Shelf 
(Div. 4TVW) stock as first suggested by Needler (1930) and confirmed by Clark and Vladykov (1960) based on vertebral counts. A western Scotian Shelf (Div. 4X) stock was proposed by Clark and Vladykov and confirmed by McCracken's (1956) tagging results. This was accepted by Grosslein but Clark and Vladykov's central shelf stock, resident between the main eastern and western shelf stocks, was ignored. Haddock off the northern shore of the Bay of Fundy (northwestern Div. 4X) were demonstrated to be the northern-most component of coastal Gulf of Maine stocks by McCracken (1960) and Grosslein recognized two coastal stock components in this area extending to the western side of the Great South Channel and implied the possible existence of several more. The separate Georges Bank stock was limited to the area east of $69^{\circ} \mathrm{W}$.

On completion of this major review of the biological basis for statistical divisions, and having taken into account in 1958 the major migrations of Gulf of St. Lawrence cod stocks, STACRES decided that the ICNAF statistical grid was "reasonably adequate" (ICNAF, 1961). It declined to make changes in Subarea 5 despite proposals for a subdivision of Div. $5 Z$ (ICNAF, 1959a) and data which indicated that the Georges Bank cod and haddock stocks should be separated from coastal stocks by a line at $68^{\circ} \mathrm{W}$ for cod (Wise, 1963) and $69^{\circ} \mathrm{W}$ for haddock (Grosslein, 1962). Very little information was available for Atlantic halibut and redfish but ICNAF did note that, for these species, "it would be advantageous not to have division lines running through deep channels between banks, but these deep channels usually separate cod and haddock populations relatively effectively" (ICNAF, 1961). Division 3 L was labelled by ICNAF (1961) as a "mixing region" for cod stocks within which collection of statistics by separate stocks was impractical. Hence, by implication, changes in boundaries would be pointless. The reluctance of ICNAF to modify boundaries, even in the face of evidence that better approximations to stock boundaries seemed possible, may have been a reflection of the view expressed by Needler (MS 1952) at the beginning of ICNAF, and reiterated by Côté (MS 1953), that the scientific benefits from fishery statistics can only be accrued if collection areas remain the same for a very long time.

\section{At Present}

Views on haddock stock structure have not changed from those summarized by Grosslein (1962). Separation of Grand Bank and St. Pierre Bank populations on the basis of biological characteristics was confirmed (Templeman and Bishop, 1979a and b; Templeman et al., 1978a and b). A study of vertebral numbers of larval and juvenile haddock on the Scotian Shelf (Tremblay et al., 1984) raised the possibility of separate stocks in Div. $4 \mathrm{~V}$ and $4 \mathrm{~W}$ but this has not yet been substantiated. A recent critical review of Gulf of Maine Area stocks (Bowen, MS 1987) found no basis to change prevailing views on stock structure.

In the case of cod, extensive vertebral counts (Templeman, 1981) and additional large tagging experiments (Templeman, 1974, 1979; Lear, 1984), particularly in the Labrador-Newfoundland area, confirmed with only slight modifications, the stock structure outlined by Templeman (1962). The major stock areas identified are locations where mixing among a complex of adjacent groups of cod is fairly high. Conversely, boundary zones are areas where mixing is reduced, presumably as a result of oceanographic and topographic barriers. These boundary zones can be complex and seasonally variable and thus not readily representable by a single line on a map. Little attention has been paid recently to separation of cod stocks in the southern part of the area (Bowen, MS 1987).

In contrast quite a bit has been learned about stock structure of other species since the last major review of boundaries almost 30 years ago. However, the two other 
groundfish species identified as next most important to cod and haddock in the early ICNAF days - redfish and Atlantic halibut, are not among those for which the knowledge base has greatly expanded. A recent review of Atlantic halibut migrations (Stobo et al., 1988), while recognizing the likely existence of several stocks, noted that there was substantial migration and intermixing, and suggested that suitable management units might be the Scotian Shelf and southern Grand Bank on the one hand and the Gulf of St. Lawrence on the other. Redfish received more research attention than Atlantic halibut but it is only in the last few years that it has been clearly recognized that there are three sympatric, and morphometrically very similar, species of Sebastes in the Northwest Atlantic (Scott and Scott, 1988). This systematic difficulty has greatly hampered biological studies. In the only comprehensive attempt to describe species population structure, Kenchington (1984) illustrated the difficulties of applying traditional stock concepts to Scotian Shelf redfish and of defining biologically meaningful geographical boundaries for management purposes.

Among other groundfish, pollock (Pollachius virens) on the Scotian Shelf and in the Gulf of Maine are now known to utilize a substantial number of areas for spawning with a great deal of intermixing occurring between spawning stocks at other lifehistory phases (Bowen, MS 1987; Mayo et al., 1989). American plaice and yellowtail flounder do not move much in their benthic phase (Lux, 1963; Pitt, 1969; Powles, 1965), and pelagic egg and larval stages, at least on the Scotian Shelf, may be retained over banks or bank systems which are smaller than current NAFO Divisions (Neilson et al., 1988). Witch flounder (Glyptocephalus cynoglossus) stocks are also considered to be highly localized (Bowering and Misra, 1982), whereas Greenland halibut are thought to be composed of one large stock extending from Davis Strait to the Grand Bank (Bowering, 1988; Templeman, 1970), although a couple of minor, localized stocks are also recognized.

For the pelagic species, Stobo et al. (1982) provided an account of the current understanding of stock structure and of the management units which have been defined for Atlantic herring (Clupea harengus) and mackerel. For herring the major migration patterns were elucidated in the 1970s through large-scale tagging experiments (NAFO, 1983; Moores and Winters, 1984; Wheeler and Winters, 1984; Winters and Beckett, 1978). It is clear that there is a substantial number of herring spawning stocks, often several within a single NAFO Division, members of which are typically highly migratory and which intermix extensively during non-spawning periods. While NAFO Divisions have been used in definition of herring management areas, particularly in an international management context, new areas have as frequently been created when circumstances allowed, e.g. in Canadian domestic management (Fig. 18 - Canada, 1989). For mackerel, the two population hypothesis of Sette (1950), with one population spawning in New England waters and the other in the Gulf of St. Lawrence, remains unmodified. For capelin (Mallotus villosus), stock structure is still conjectural, although their widespread coastal demersal spawning habit indicates that there are likely a great many stocks. Five major groupings have been proposed, and are used by Canada and NAFO for management purposes, with mixing during nonspawning periods recognized even among some of these (Campbell and Winters, MS 1973; Carscadden and Misra, 1980; Misra and Carscadden, 1984).

Short-finned squid (IIlex illecebrosus) has been managed on a broad geographical basis, reflecting the view that they comprise a single stock which uses the Gulf Stream to disperse young stages throughout much of NAFO Subareas 3-6 (Dawe et al., 1984). Management of other invertebrate species has tended to be on a much smaller geographical scale. For example, in the Canadian context (CAFSAC, 1988) snow crab 


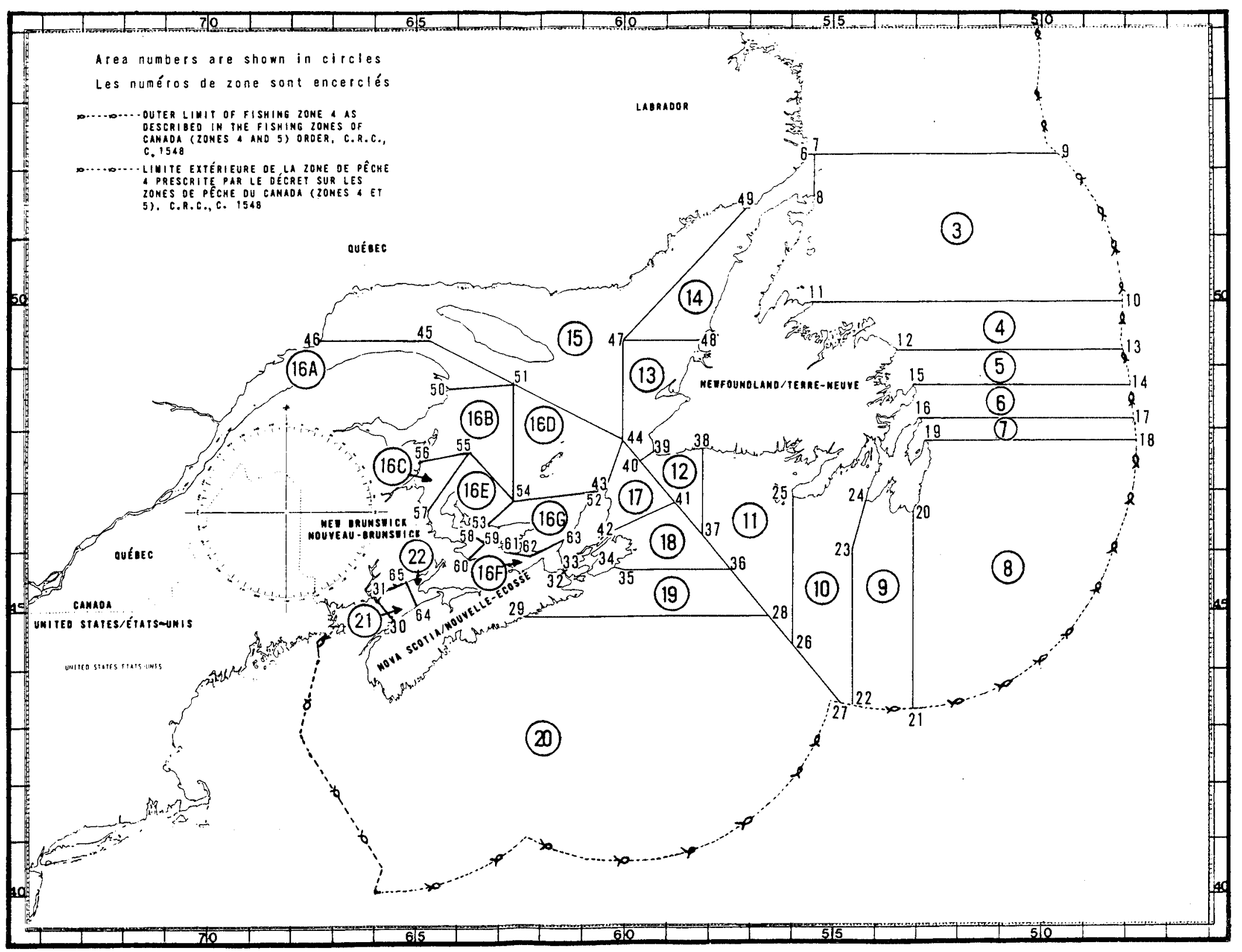

Fig. 18. Canadian herring fishing areas defined for management purposes (from Canada, 1989). 
(Chionoectes opilio), shrimp (Pandalus borealis), scallops (Placopecten magellanicus) and lobster (Homarus americanus) are managed on the basis of commercial concentrations which may correspond in some cases to biological stocks, e.g. scallops (Sinclair et al. 1985a) but in other cases, e.g. lobsters (Campbell and Mohn, 1983), probably do not. For each of these species Canadian regulations define different management areas which retain some NAFO boundaries but have many unique features.

In summary, as knowledge of stock structure has accumulated for a diversity of species over the last 30 years, there has developed a greater appreciation that the biology of marine species is organized on a variety of geographical scales, i.e. they vary greatly in their population patterns and richness. Some species may maintain a stock structure on a scale large by comparison to NAFO Divisions, e.g. short-finned squid and mackerel, but for many species more than one spawning stock may occur within a single Division, e.g. cod, herring and some flatfish. Among the latter, nonspawning stages may range over Division boundaries and intermix extensively, e.g. cod and herring, but in the case of flatfish individuals may complete their life-cycle within localized areas. In yet other species, exploited stages may be relatively sedentary and fishery concentration may occur on a small scale, but recruitment mechanisms may function on a much broader geographical basis, e.g. redfish and some invertebrate species. Based on present knowledge, it seems that NAFO Divisions are on the meso-scale in relation to the geography of stock divisions for the commercial species in the area.

\section{Discussion}

\section{Do Fishing Areas Correspond to Stock Areas?}

The definition of fishing areas in the Northwest Atlantic has been based on considerations of biological stock structure, species and fishery distributions, oceanographic features, submarine topography, political and administrative boundaries, homogeneity of fisheries participation (internationally), and practicalities of data collection and fishery regulation. In many cases several considerations concurrently supported the choice of fishing area boundaries. In particular, deep channels were favoured locations for boundaries as these separated banks, which supported discrete fisheries, and apparently also discrete stocks of the primary commercial species, cod and haddock. Water circulation patterns were also greatly influenced by banks. These considerations tended to be weighed heavily during decision-making about smallscale subdivisions. Political, administrative and regulatory issues were weighed more heavily in definition of large-scale areas.

Both NACFI and ICNAF consistently identified stock structure as the primary criterion for area definition. In actuality, NACFI had almost no information on stock structure available to it, except a broad-scale subdivision of haddock populations, when it made its crucial decisions in 1931-32. There is ground for conjecture that the committee saw itself as defining general ecological regions as reflected in the nature of the fauna and the distribution of the fisheries, rather than purely statistical areas, but this concept is not explicitly stated in their reports. In 1949-53, when the various ICNAF boundaries were decided upon, substantially more was known about cod stocks although most of the information was still provisional and speculative. When a great deal firmer information on cod and haddock stock structure became available in 1958-62, STACRES placed emphasis on the practical consideration of maintaining 
continuity and made changes only where the need was uncontestable (subdivision of Div. 4V and 3P). Against this background, the agreement of STACRES in 1967 (ICNAF, 1967) to split Div. $5 Z$ into subdivisions without reference to documentation and at a location $\left(70^{\circ} \mathrm{W}\right.$ ) inconsistent with earlier analysis for cod and haddock (Grosslein, 1962; Wise, 1963; Wise and Jensen, MS 1960) is incongruous.

It is clear that biological stock structure has not had an overriding influence on fishing area definition. Information on stock separation was available only for cod and haddock, and this was to large extent taken into account when NACFI and ICNAF made their crucial boundary decisions, reflecting the overriding importance of these species to the fishery at these times. In 1954-55, the first years for which comprehensive statistics for Northwest Atlantic fisheries are available, cod and haddock composed about $60 \%$ of total landings from the Convention Area. In 1931-32, cod and haddock composed over $70 \%$ of total landings from this same area. (An exact percentage cannot be derived for that earlier period as composite statistics for pelagic and invertebrate species are not readily available, but these species were clearly no more important then than in 1954-55 when they comprised less than $20 \%$ of the landings.) In contrast, Northwest Atlantic fisheries were much more diversified in the mid-1970s when the new NAFO Convention was under consideration. Cod and haddock composed only $22 \%$ of the landings in $1975-76$, just prior to extensions of coastal state jurisdiction. However, although there had been improvements in knowledge of stock structure for a diversity of important species, there is no evidence that a change in boundaries was given any consideration, despite the opportunity that was provided with the negotiation of a new convention. At this juncture, scientific attention was focused on the need for fine-scale statistical reporting and some scientists foresaw management areas being defined as combinations of small statistical units which varied for different species or groups of species (e.g. Brown, MS 1974). The new knowledge on stock structure illustrated that a simple geographical grid could not capture the complexities of population structure, particularly in the southern part of the ICNAF Statistical Area (Subareas 4-5 and Statistical Area 6) where species diversity is higher. It would be misleading to suggest that there was a scientific consensus that ICNAF Divisions were about to become redundant with the institution of fine-scale reporting. In more northern areas (Subareas 1-3) cod continued to support the most important fishery (composing about $40 \%$ of the total landings) and ICNAF Divisions appeared as satisfactory for that species in 1975-76 as they had in 1958-62 and, even in southern areas, continuity of reporting was valued highly. It is safe to say, however, that, by the mid-1970s, there was no consensus that a revision of the ICNAF Division system offered per se a means to significantly improve the basis for management in the area.

\section{Need Fishing Area and Stock Boundaries Coincide?}

The concept that effects of fishing on fish species must be analyzed on a stock basis influenced fishing area delineation in the Northwest Atlantic from the 1930s (Found, 1933; Rounsefell, 1948). It was implicit that management of fisheries should control exploitation also on a stock basis. The establishment of this "population thinking" in fisheries biology in the early decades of this century has recently been described by Sinclair and Solemdal (1988).

It transpired, however, in the case of trawl mesh size regulations imposed from the 1950s, that mesh size could be standardized over large areas and a number of species. Despite differences in population parameters among stocks and even among species, differences in potential yields at different mesh sizes were not sufficient to outweigh 
the practical advantage of standardization. It also transpires that similar generalizations are possible when it comes to target exploitation levels associated with a particular management strategy, e.g. $F_{0.1}$ for cod approximates 0.20 for all stocks. Thus, any mechanisms which spread catch over area in proportion to cod abundance (but not necessarily to density or proximity to home port) would result in all cod stocks being fished at about the same level in relation to the target. As this could be achieved using a grid which is arbitrary in relation to stock boundaries, then clearly, gross errors in the location of management boundary lines in relation to stock boundaries need not prejudice management success.

Problems may arise, of course, when it is necessary to follow different management strategies for different stocks, e.g. the ban of fishing on badly depleted stocks. Clearly, if an important part of the protected stock is subject to fishing in adjacent areas the depleted stock could be subject to a substantial amount of fishing. In the case of highly migratory species this is a crucial issue. Herring management considerations have been dominated by the problems of migration and stock mixing and this has led to proposals that management should be concerned a great deal more with the distributional aspects of fishing mortality (Sinclair et al., 1985b).

Interestingly, in the history of management through TACs of Northwest Atlantic groundfish, which now extends for close to 20 years, stock boundaries have not often arisen as the potential basis for scientific or management problems. Although difficulties in interpretation of data and apparent stock assessment errors are regular occurrences, these are interpreted in terms of data deficiencies or limitations in analytical (mathematical and statistical) methods. Answers have not normally been sought through evaluation of the appropriateness of the assessment unit definition despite the sensitivity of sequential population analysis (Ulltang, 1977) and other assessment methods to the assumption of stock integrity. An exception is the recent Canadian decision to spread offshore fleet catches from the Div. 2J and 3KL cod management unit equally over Divisions (Canada, 1987) in order to spread mortality more evenly over stock components within the unit. However, this action stemmed mainly from concerns in the industry about distributional effects of offshore catches on inshore fishing prospects, rather than resulting from the tentative expressions of scientific concern (NAFO, 1986b) that the underlying assumption for stock assessment of complete mixing throughout the stock complex clearly was not met. More recently Canadian scientists have revised the stock assessment units for Georges Bank cod and haddock, restricting these to "subareas" $j$ and $m$ (Fig. 6) in Div. $5 Z$, i.e. to east of $67^{\circ} 40^{\prime} \mathrm{W}$, to better reflect historical evidence on stock distribution (CAFSAC, MS 1989), and to thus improve the correspondence between assessment and management units and stock structure.

Despite lack of attention to the adequacy of defined management units in the Northwest Atlantic there has been no challenge to the concept that the geographical scale for scientific assessment, and for management measures to control exploitation rate, should correspond to that of biological stocks and that this geography should be reflected in the delineation of fishing areas. Thus the pertinent question is, how is this to be achieved given the complexity of differing stock boundaries for different species? An important ancillary issue, which cannot be addressed here, is how close an approximation between stock, statistical/assessment and management areas is necessary to lay a sound basis for management? (Statistical and assessment areas cannot be treated separately given the integral part fisheries statistics play in assessment.) Historical practice suggests that it has been the hope, if not the considered view, of scientists that crude approximations of statistical/assessment areas, and hence management areas, to stock distributional areas are good enough. 


\section{Modern Needs for Area of Capture Data}

Administrative and Regulatory: From an administrative viewpoint, historical interest has been on landings statistics. It was only in the early-1970s with the introduction by ICNAF of TAC regulation and fleet catch allocations that an administrative interest in area of capture data became necessary. An early example of this interest was the retroactive estimation of catches inside and outside the ICNAF Convention Area when this became important in estimation of Convention Area allocations. While such inferred catch distributions may have been satisfactory at the initial stages of TAC implementation, the ongoing regulatory activity of monitoring and enforcement of catch quotas, which had an immediate impact on fishermen's livelihood, required the support of a statistical system which collected catch data by areas of capture which could be equated with regulatory areas. Regulation of catches by non-standard areas proved difficult or impossible. Indeed, the above account provides ample demonstration that the statistical framework defines the scope for effective management action.

Extensions of fisheries jurisdiction created a variety of new administrative boundaries in the Northwest Atlantic. As none of these corresponded with the statistical boundaries used in the ICNAF catch quota regime, a large number of statistical and management areas overlapped these new administrative boundaries. The administrative and regulatory convenience of incorporating jurisdictional boundaries into the statistical grid was recognized by Canada in successful proposals to adjust Subarea and Divisional boundaries to coincide with the Canada-Greenland and Canada-USA maritime boundaries. This provided a method to record and maintain a published record of international fisheries data in relation to areas of jurisdiction, and thus a clear basis on which adjacent states could discuss matters of common interest such as national shares of transboundary resources. It also eliminated the nominal transboundary status of a number of resources and paved the way for national management. ("Nominal" transboundary resources are those for which the management unit in use had no strong basis in biology.) Maintaining international arrangements for resource management can be both difficult and costly, hence minimizing the necessity for them would appear to have virtue.

In light of these actions it is anomalous that no steps have been taken to codify the boundary between coastal state waters and those of the NAFO Regulatory Area into the statistical system. This offers particular advantages in the Grand Bank area (Div. 3LNO) where the boundary between Canadian and Regulatory Area waters splits a region which supports widespread groundfish fisheries. Disparate fisheries in terms of participation and fishing intensity now occur on either side of this boundary. Availability of comprehensive fisheries statistics for the two areas could allow for improvement in stock assessments and also provide administrators with greater scope to explore innovative management solutions.

While Canada continues to use NAFO Divisions for groundfish management, which has an international dimension, a diversity of geographical grids have been established on a species basis for domestic pelagic fish and invertebrate species management, such as that illustrated for herring in Fig. 18. While a variety of the lines delimiting these species management areas correspond to NAFO Division, or the smaller groundfish "subarea", boundaries, many are unique. No systematic adjustments have been made in statistical data collection, however, to codify these areas. Catches are assigned to management areas as approximated by Division or groundfish "subarea" of capture (possibly supplemented with Fishery District of landing information or other ancillary data). While this ad hoc approach may prove satisfactory, at least in the short term, it illustrates the limitations of the NAFO grid for TAC management of pelagic and invertebrate species. 
Scientific: The purpose of obtaining commercial fishery statistics was to determine trends in abundance of stocks so that populations could be maintained, through fishery control measures, at levels which maximized long-term yields (Needler, MS 1952; Rounsefell, 1948). The need for a geographical scale which approximated that of fish stocks was recognized in the crucial decisions in 1953 on ICNAF Divisions, but practical considerations, particularly the difficulty of obtaining accurate, comprehensive statistics by small areas, also weighed heavily. The view that these Divisions would provide an adequate basis for fishery science and management can be understood only in terms of the traditional nature of contemporary fisheries. Patterns of fishing changed little from year to year, providing some basis for the hope that data would be comparable over long periods even within large areas. However, such a view could not have been sustained for long. In the late-1950s technological developments, the key element of which was the introduction of the factory-freezer stern trawler, revolutionized the fisheries, and in the mid-1970s extensions of fisheries jurisdiction radically changed their nature once again. In addition, institution of detailed management controls in the early-1970s modified fishermen's behaviour and further detracted from the value of time-series data.

There was a persistent view that ICNAF Divisions were on too gross a scale for many biological needs, and in particular for the determination of trends in abundance based on the fishing performance of commercial fleets. Rounsefell (1948), in his description of the smaller-scale "subarea" system, expressed the need for commercial catch and fishing effort data from areas of homogeneous density. The theoretical basis for this requirement for unbiased estimation of abundance was fully elaborated by Gulland (1955) and Beverton and Holt (1957). Rounsefell (1957) himself demonstrated, based on analysis of $10^{\prime}$ graticule data for Georges Bank fisheries, that there was a great deal of heterogeneity in fish and fishery distributions even within areas at the "subarea" scale.

The intensive efforts of ICNAF in the early-1970s to obtain control over exploitation rates made clear the inadequacies of data on a Divisional basis. The diversification of fisheries had increased the difficulties in interpreting commercial catch-rate data for stock abundance estimation. The development of mixed fisheries created particular problems in data analysis and in formulation of adequate regulations for control of species-specific exploitation rates. Indeed, it was difficult to discern to what extent the "mixed fishery problem" truly reflected fishing patterns and to what extent it was an artifact of data amalgamation. Analytical efforts to provide a basis for fishing effort regulation were also hampered. Furthermore, regulatory efforts involved a diversity of species and increasing knowledge about stock structure made it clear that, in a number of important cases, Divisions did not provide a suitable geographical basis for regulation. It was for these reasons that STACRES accepted the need to institute data collection based on a 30' graticule (ICNAF, 1974).

It has also long been recognized that Divisional-scale fishery data are inadequate for dealing with a class of issues which could be categorized as being "geographical" in nature. A traditional fishery management-related issue of this type is the definition of closed areas for conservation purposes (e.g. Halliday, 1988). Evaluation of the impact of physical or chemical discharges into the ocean, e.g. from oil and gas wells, on commercial fisheries has also been an important issue. Extensions of jurisdiction brought boundary disputes and the need to describe potential impacts of alternative boundaries on the fisheries of the disputing parties. Resolution of such disputes has resulted in proposals to change statistical boundaries, requiring analysis of fine-scale fishery distributions. Data collected on the basis of the finer "subareas" has proven 
also to be on too coarse a scale for these purposes and it has often been necessary to revert to original fishing log book data, or to use surveillance or research vessel data where this is possible (e.g. Halliday et al., 1986).

Scientific research in support of present day fisheries management clearly requires fishery data on a scale much finer than Divisions. It is equally true that, had Divisions not existed in the early-1970s, institution of catch quota management would have required creation of management units on a scale which, on average, may have approximated Divisions in size. The continuing controversy over scale has arisen from trying to have a single statistical grid serve two purposes. The solution lies in adoption of a hierarchical system composed of fine scale research units which are combinable into larger scale management units. In addition to the obvious advantage of providing grids suitable to each purpose, this addresses the primary deficiency of the present Division system as a management grid - its inflexibility. It is self-evident that reformulation of the management grid requires availability of the fine scale data contained in the research grid if the integrity of the time-series of data needed for management is to be retained.

In the early-1950s (and for some time afterwards) navigational charts were not precise and arguments could be made about the accuracy of fine scale data (e.g. Côté, MS 1953). The greatest handicap, however, was probably the need for all data to be processed manually. However, developments in navigation and electronic data processing have made it increasingly possible to collect data on a finer scale. As a result, coastal states have been capturing data for their own use on scales substantially smaller than Divisions, particularly after jurisdictional extensions. These scales vary, but the ultimate breakdown is being achieved for some data sets with the position of each vessel haul being recorded and retained in statistical systems by its latitude and longitude. Records by a $10^{\prime}$ or $15^{\prime}$ graticule are close to this scale, as a vessel may traverse a single cell of such a graticule within one haul. Clearly, it is now practical to achieve this level of detail in fishery statistical systems, at least for larger vessels. Although equally desirable, it is less easy to achieve such detail for fleets of small coastal vessels. Detailed record-keeping is more difficult on very small boats with few crew members and hence record collection presents a greater logistical challenge. It is an advantage of a graticule system that data can be collected on various scales which are multiples of the basic graticule (e.g. $\left.10^{\prime}, 20^{\prime}, 40^{\prime}\right)$, allowing data to be recorded at the resolution available for particular fleets or fisheries. Thus, ability to collect all data at the level of the finest scale graticule (e.g. 10') is not a prerequisite for adoption of a graticule system. Admittedly, the coarser the scale used the more difficult it is to amalgamate data in conformity with present Divisional and jurisdictional boundaries, i.e. the larger the graticule used the greater will be the area of the rectangles transected by boundaries with the result that there will be doubt about the Division (or jurisdiction) of origin of a greater proportion of the catch. It may be necessary, when data are collected on a coarse scale, to also collect data on Division and jurisdicational area. However, if low geographical resolution is inherent in the original catch data, e.g. if fishermen cannot, or refuse to, record data accurately, or if the gear fished covers many miles in a single fishing operation, an arbitrary assignment of graticule-based data to Division or jurisdictional area is unlikely to introduce significant additional locational error. The arbitrary assignment could be based on knowledge about fishing patterns, e.g. from surveillance, or on a proration by proportional area of the graticule on either side of a boundary. A nested hierarchal system would result in all data being available with a resolution much finer than Division and it seems unlikely that there would be any degradation in accuracy of catch statistics at the Division level. With regard to scientific requirements, however, it is unlikely that biologists will be truly satisfied with area of capture statistics until essentially all data are available on a scale of $10^{\prime}$ or $15^{\prime}$ rectangles. 


\section{Thoughts to the Future}

The NAFO Scientific Council is obligated by the NAFO Convention (Article VI) "to compile and maintain statistics ... pertaining to the fisheries of the Convention Area" for the purposes of promoting scientific study of regional fisheries resources and provision of advice on their management to coastal states (which are signatories to the Convention) and the Fisheries Commission. In its 10 year history the Scientific Council has served as custodian of the statistical system it inherited from ICNAF but has not been innovative in its further development either for the Regulatory Area, for which it has sole responsibility, or for the Convention Area, for which it has the authority to play a coordinating role. Can this be considered as a satisfactory fulfilment of the Scientific Council's obligations?

The anticipation of STACRES in 1977 that coastal states would establish their own reporting requirements for foreign (and of course, domestic) vessels fishing in their newly-extended regulatory zones caused postponement of the ICNAF 30' graticule system. Coastal states did, indeed, establish various (and different) requirements for area-of-capture data to meet management needs for resources within national zones. However, a significant proportion of Northwest Atlantic resources remains of international interest either bilaterally between adjacent coastal states, multinationally within the NAFO Regulatory Area, or between NAFO and adjacent coastal states. As Regulatory Area catches are available only by NAFO Division, this remains the "lowest common denominator" on an international level. In this international context the Scientific Council would seem to have a legitimate and valuable role to play in ensuring adequate statistics are available to meet management needs, as well as for promotion of scientific research. It is important to recognize that while the original act of recording data is a necessary condition for making these data available for use, it is not a sufficient condition. These data must be compiled and maintained in a form suitable and readily accessible to users. Thus while fine scale data are recorded, and usually also compiled by national agencies, for a substantial proportion of Northwest Atlantic fishery activities, this does not necessarily meet users' needs with regard to form or accessability. The obligation conferred on the Scientific Council by the Convention is to maintain an international data base which does meet these needs, at least for international fisheries.

If the Scientific Council should take a more active role in development of the statistical system, what should it do? The present review makes it clear that the NAFO Divisional system has little inherent virtue other than continuity. However no alternative grid on the same scale offers significant advantages for management of the diverse modern fisheries. The most significant improvement in area-of-capture data would be derived from the institution of a hierarchical system which would provide the flexibility to store and retrieve data on a variety of scales suitable for the diverse needs of users. A graticule system offers the best solution as it provides the greatest flexibility. It is beyond the scope of this review to devise such a system but it is obvious that much of the data must be captured on a scale no greater than $10^{\prime} \times 10^{\prime}$ or $15^{\prime} \times 15^{\prime}$ rectangles to meet scientific needs. It is perhaps worth reiterating that, conversely, this does not preclude some data being collected on coarser scales which are multiples of the basic graticule should this prove to be necessary during a phase-in period or satisfactory in the long term. If comprehensive area-of-capture data became available on a graticule system for the Convention Area, NAFO would be in a position to produce data summaries by a variety of larger scale areas which might be of interest to Contracting Parties, in addition to traditional summaries by Division. The way would thus be open to define as management units areas other than Divisions with the assurance that the statistical infrastructure was available to support regulation on that basis. 
These changes will take time to implement. In the meantime there are some specific changes to the NAFO Divisional grid which are clearly worthwhile to effect in the short term. Codification of the Regulatory Area boundary into the grid is the most obvious of these. This would provide a statistical basis for more informed, flexible and innovative approaches to transboundary management issues as well as an improved basis for stock assessment.

It would be worthwhile also for the scientific community to examine the question of just how accurately management boundaries need to coincide with stock boundaries, i.e. the extent to which stock assessment and management problems originate from violations of the underlying assumption of management on the basis of stocks. Shepherd (1988) recently commented on the same point in a general context, thus lack of attention to this issue is by no means a local problem.

\section{Acknowledgements}

The late L. R. Day investigated the history of statistical lines in connection with the boundary resolution between Canada and the USA in the Gulf of Maine. His work stimulated our interest in, and broadened our perspective of, the general question of fishing area delimitation. Sv. Aa. Horsted and $H$. Lassen, and R. Mayo, provided information on Danish (Greenlandic), and USA, statistical systems respectively. Carla Dale provided technical assistance. We are grateful to M. D. Grosslein, R. C. Hennemuth, Sv. Aa. Horsted, R. Mayo, A. W. H. Needler, M. Sinclair, and the late W. Templeman for reviewing the paper and providing valuable comments and corrections. 


\section{References}

ATKINSON, D. B., W. R. BOWERING, D. G. PARSONS, Sv, Aa. HORSTED, and J. P. MINET. 1982. A review of the biology and fisheries for roundnose grenadier, Greenland halibut and northern shrimp in Davis Strait. NAFO Sci. Coun. Studies, 3: 7-27.

BEVERTON, R. J. H., and S. J. HOLT. 1957. On the dynamics of exploited fish populations. Fish. Invest. Lond., Ser. 2, 19: $533 p$.

BIGELOW, H. B. 1928. Physical oceanography of the Gulf of Maine. Bull. U.S. Bur. Fish., 40(2): 1027 p. (Doc. 969).

BOWEN, W. D. (ed.). MS 1987. A review of stock structure in the Gulf of Maine Area: a workshop report. CAFSAC Res. DOC., No. 21, 51 p.

BOWERING, W. R. 1988. An analysis of morphometric characters of Greenland halibut (Reinhardtius hippoglossoides) in the Northwest Atlantic using a multivariate analysis of covariance. Can. J. Fish. Aquat. Sci., 45: 580-585.

BOWERING, W. R., and R. K. MISRA. 1982. Comparisons of witch flounder (Glyptocephalus cynoglossus) stocks of the Newfoundland-Labrador area, based upon a new multivariate analysis method for meristic characters. Can. J. Fish. Aquat. Sci., 39: 564-570.

BROWN, B. E. MS 1974. Species mixture in the boundary areas between $5 Z$ Ze and $5 Z$ w. ICNAF Res. Doc., No. 101, Serial No. $3337,6 \mathrm{p}$.

BURNS, T. S., and R. L. SCHULTZ. MS 1989. Manual for sampling, interviewing and coding for the Northeast Region. U.S. Nat. Mar. Fish. Serv., Northeast Fisheries Center, unpublished manuscript.

CAFSAC. 1988. Canadian Atlantic Fisheries Scientific Advisory Committee. Ann. Rep., 10: 374 p.

MS 1989. Advice on the management of groundfish stocks in 1990. CAFSAC Adv. Doc., No. 12, $82 \mathrm{p}$.

CAMPBELL, A., and R. K. MOHN. 1983. Definition of American lobster stocks for the Canadian Maritimes by analysis of fishery-landing trends. Trans. Amer. Fish. Soc., 112: 744-759.

CAMPBELL, J. S., and G. H. WINTERS. MS 1973. Some biological characteristics of capelin, Mallotus villosus, in the Newfoundland area. ICNAF Res. Doc., No. 90 , Serial No. 3048,8 p. + Addendum

CANADA. 1920. Fifty-third annual report of the Fisheries Branch, Department of Naval Service, for the year 1919. King's Printer, Ottawa.

MS 1972. Cod and haddock landings from Subarea 4 of the Convention Area, 1958-70. ICNAF Comm. Doc., No. 32, Serial No. 2869, 5 p.

MS 1985. Modifications to Subarea 4-5 boundary. NAFO GC DOC., No. 6, Serial No. N1046, 1 p.

MS 1986. Canadian proposal for modifications to Annex III of the NAFO Convention-scientific and statistical Subareas, Divisions and Subdivisions. NAFO GC Doc., No. 2 (2nd Revision), Serial No. N1202, 2 p.

1987. Atlantic groundfish management plan 1988. Department of Fisheries and Oceans, Ottawa, $111 \mathrm{p}$.

1989. Atlantic Fishery Regulations, 1985, amendment. Canada Gazette Part II, Vol. 123, No. 9: 2267-2276.

CARSCADDEN, J. E., and R. K. MISRA. 1980. Multivariate analysis of meristic characters of capelin (Mallotus villosus) in the Northwest Atiantic. Can. J. Fish. Aquat. Sci., 37: $725-729$.
CLARK, J. R., and V. D. VLADYKOV. 1960. Definition of haddock stocks of the Northwestern Atlantic. Fish. Bull. U.S., 60(169): 283-296.

CÔTÉ, J. MS 1953. Subdivision of Subareas. ICNAF Meet. Doc., No. 18, Serial No. 90,2 p.

DAWE, E. G., M. C. MERCER, and W. THRELFALL. 1984. On the stock identity of short-finned squid (Illex illecebrosus) in the Northwest Atlantic. NAFO Sci. Coun. Studies, 7 : 77-86.

DeBAIE, B. F. C. MS 1964. Survey of geographic grid systems now in use by various countries for the ICNAF and ICES areas. ICNAF Meet. Doc., No. 10, Serial No. 1299, 9 p.

FAO. 1962. Requirements and improvement of fishery statistics in the North Atlantic region. FAO Fish. Rep., 3:217 p.

1963. Report of the third session - Continuing Working Party on Fishery Statistics in the North Atlantic Area. FAO Fish. Rep., 7: $37 \mathrm{p}$.

MS 1964. Proposal for a standard international statistical classification of fishing areas. ICNAF Meet. DOC., No. 91. Serial No. 1387, $31 \mathrm{p}$.

1984. Report of the twelfth session of the Coordinating Working Party on Atlantic Fishery Statistics. FAO Fish. Rep., 316: $60 \mathrm{p}$.

FLEMING, A. M. 1960. Age, growth and sexual maturity of cod (Gadus morhua L.) in the Newfoundland area, 1947-50.J. Fish. Res. Board Can., 17: 775-809.

FOUND, W. A. 1933. North American Council on Fishery Investigations. Third annual report of the Department of Fisheries for the year 1932-33. Ottawa, p. 25-27.

GERTENBACH, L. P. D. MS 1967. Proposals for the collection of statistics for the waters to the south of the ICNAF Convention Area. Fifth session of the Continuing Working Party on Fishery Statistics in the North Atlantic Area. STANA: 5/67/8E, 12 p.

GROSSLEIN, M. D. 1962. Haddock stocks in the ICNAF Convention Area. ICNAF Redbook, 1962(III): 124-131.

GULLAND, J. A. 1955. Estimation of growth and mortality in commercial fish populations. Fish. Invest. Lond., Ser. 2. 18(9): $46 \mathrm{p}$.

1983. Fish stock assessment. FAO/Wiley Series on Food and Agriculture, V.1. John Wiley and Sons, Chichester. $223 \mathrm{p}$.

HACHEY, H. B., F. HERMANN, and W. B. BAILEY, 1954. The waters of the ICNAF Convention Area. ICNAF Ann. Proc., 4: $67-102$.

HALLIDAY, R. G. 1988. Use of seasonal spawning area closures in the management of haddock fisheries in the Northwest Atlantic. NAFO Sci. Coun. Studies, 12: 27-36.

HALLIDAY, R. G., J. MCGLADE, R. MOHN, R. N. O'BOYLE, and M. SINCLAIR. 1986. Resource and fishery distributions in the Gulf of Maine Area in relation to the Subarea 4/5 boundary. NAFO Sci. Coun. Studies, 10: 67-92.

HANSEN, P. M. 1949. Studies on the biology of cod in Greenland waters. ICES Rapp. Proc.-Verb., 123: 1-77.

HAZEL, J. E. 1970. Atlantic continental shelf and slope of the United States - ostracod zoogeography in the southern Nova Scotian and northern Virginian faunal provinces. U.S. Geol. Surv. Prof. Paper 529-E: v $+29 p$.

ICES. MS 1982. Report of the ad hoc working group on fishing area boundaries. ICES C.M. Doc., No. D:2, 14 p.

ICNAF. 1951. Report of the first annual meeting, with appendices. ICNAF Ann. Rep., 1: 53 p.

MS 1952a. Report for second annual meeting re 
fishery statistics in the Convention Area. ICNAF Meet. Doc., No. 8, Serial No. 51, 22 p.

MS 1952b. Second report of Committee on Research and Statistics. ICNAF Meet. Doc., No. 18, Serial No. 60 , $17 \mathrm{p}$.

MS 1953a. Third annual meeting, fourth and final plenary session. ICNAF Meet. Proc., No. 18, Serial No. 131, $4 p+$ appendix

MS 1953b. Progress report on statistics. ICNAFMeet. Doc., No. 30 , Serial No. $102,18 \mathrm{p}$.

1956. Summary of the fishery in the Convention Area. ICNAF Stat. Bull., 4: 7-18.

MS 1957. Report of scientific advisers to Panel 5 on revision of statistical divisions. App. $V$ to report of combined meeting of Panels 3, 4 and 5. ICNAF Meet. Proc., No. 8, Serial No. 489,2 p. + appendices.

1958. Report of the ad hoc subcommittee on sampling of eastern Subarea 4 cod stocks. App. 8 to report of the Standing Committee on Research and Statistics. ICNAF Redbook, 1958: 30-32.

1959a. Report of December 1958 meeting of scientific advisers to Panels 4 and 5. ICNAF Redbook, 1959: 5-18.

1959b. Report of the ad hoc subcommittee on statistical areas. App. XI of report of the Standing Committee on Research and Statistics. ICNAF Redbook, 1959: p. 79.

1960a. Statistical Bulletin Vol. 8 for the year 1958, p. 3 (footnote).

1960b. Report of the meeting of the Standing Committee on Research and Statistics. ICNAFRedbook, 1960: 5-49.

MS 1960. Basic statistical unit areas. ICNAF Meet. Doc., No. 5, Serial No. $721,6 \mathrm{p}$

1961. Report of the meeting of the Standing Committee on Research and Statistics. ICNAF Redbook, 1961: 3-51.

1962. Proceedings of the Standing Committee on Research and Statistics. ICNAF Redbook, 1962(1), 48 p. 1963. Report of the statistics subcommittee. App. 6 to the report of Standing Committee on Research and Statistics. ICNAF Redbook, 1963(1): 65-74.

1964. Report of the subcommittee on statistics. App. 8 to the report of Standing Committee on Research and Statistics. ICNAF Redbook, 1964(1): 76-82.

1966. Report of Standing Committee on Research and Statistics. ICNAF Redbook, 1966(1), $90 \mathrm{p}$.

1967. Report of Standing Committee on Research and Statistics. ICNAF Redbook, 1967(1), 79 p.

MS 1967. Annual nominal catch and common and scientific names of fish taken from the region southward of the ICNAF Convention Area to the latitude of Cape Hatteras, 1963-66. ICNAF Res. Doc., No. 51, Serial No. 1839, $6 \mathrm{p}$.

1971. Report of Standing Committee on Research and Statistics. ICNAF Redbook, 1971(1), 83 p.

1972a. Report of joint meeting of Panels 2 and 3. ICNAF Meet. Proc., 1972: 99-100.

1972b. Report of Standing Committee on Research and Statistics. ICNAF Redbook, 1972(1), 87 p.

MS 1972. More detailed catch/effort reporting ICNAF Res. Doc., No. 98, Serial No. 2826, 6 p.

1973. Report of Standing Committee on Research and Statistics, Annual Meeting June 1973. ICNAF Redbook, 1973,(1): 51-122.
1974. Standing Committee on Research and Statistics proceedings. ICNAF Redbook, 1974, $154 \mathrm{p}$.

1975a. New Statistical Area in Northwest Atlantic. ICNAF Stat. Bull., 23: 277.

1975b. Report of joint meeting of Panels 1-5. ICNAF Meet. Proc., 1975: 263-264.

1977. Report of Standing Committee on Research and Statistics. ICNAF Redbook, 1977: 33-87.

1978. Report of Standing Committee on Research and Statistics. ICNAF Redbook, 1978: 7-20.

JEAN, Y. 1963. Where do Seven Islands cod come from? Fish. Res. Board Can., Atl. Biol. Sta. Circ. (Gen. Ser.), 39, 2 p.

JONES, C. MS 1978. Standardization of Canadian east coast statistical Unit Areas. CAFSAC Res. Doc., No. 32 (Revised), $52 \mathrm{p}$.

KENCHINGTON, T. J. 1984. Population structures and management of the redfishes (Sebastes spp.: Scorpaenidae) of the Scotian Shelf. Ph.D. Thesis, Dalhousie Univ., Halifax, N.S., Canada, 491 p.

LEAR, W. H. 1984. Discrimination of the stock complex of Atlantic cod (Gadus morhua) off southern Labrador and eastern Newfoundland, as inferred from tagging studies. J. Northw. Atl. Fish. Sci., 5: 143-159.

LUX, F. E. 1963. Identification of New England yellowtail flounder groups. Fish. Bull. U.S., 63: 1-10.

MARTIN, W. R. 1953. Identification of major groundfish stocks in Subarea 4 of the Northwest Atlantic Convention Area. ICNAF Ann. Proc., 3: 57-61.

1959. Canadian research report, 1958, B. Subareas 4 and 5. ICNAF Ann. Proc., 9: 26-31.

MARTIN, W. R., and Y. JEAN. 1964. Winter cod taggings off Cape Breton and on offshore Nova Scotia banks. J. Fish. Res. Board Can., 21: 215-238.

MAYO, R. K., J. M. McGLADE, and S. H. CLARK. 1989. Patterns of exploitation and biological status of pollock (Po/lachius virens L.) in the Scotian Shelf, Georges Bank, and Gulf of Maine area. J. Northw. Atl. Fish. Sci., 9: 13-36.

MCCRACKEN, F. D. 1956. Cod and haddock tagging off Lockeport, N.S. Fish. Res. Board Can. Atlant. Prog. Rep., 64: $10-14$.

1958. On the biology and fishery of the Canadian Atlantic halibut, Hippoglossus hippoglossus L. J. Fish. Res. Board Can., 15: 1269-1311.

1959. Cod tagging off northern New Brunswick in 1955 and 1956. Fish. Res. Board Can. Atlant. Prog. Rep., 72: 8-19.

1960. Studies of haddock in the Passamaquoddy Bay region. J. Fish. Res. Board Can., 17: 175-180.

MCKENZIE, R. A. 1934. Cod movements on the Canadian Atlantic coast. Contrib. Can. Biol. Fish. (New Ser.), 8(31): 435-458.

1956. Atlantic cod tagging off the southern Canadian mainland. Bull. Fish. Res. Board Can., 105, 93 p.

MCKENZIE, R. A., and G. F. M. SMITH. 1955. Atlantic cod populations along the southern Canadian mainland as shown by vertebral count studies. J. Fish. Res. Board Can., 12: 698-705.

MISRA, R. K., and J. E. CARSCADDEN. 1984. Stock discrimination of capelin (Mallotus villosus) in the Northwest Atlantic. J. Northw. Atl. Fish. Sci., 5: 199-205.

MOORES, J. A., and G. H. WINTERS. 1984. Migration patterns of Newfoundland west coast herring, Clupea harengus, as shown by tagging studies. J. Northw. Atl. Fish. Sci., 5: $17-22$. 
NACFI. 1932. North American Council on Fishery Investigations Proc. 1921-1930, No. 1, King's Printer, Ottawa, $56 \mathrm{p}$. 1935. North American Council on Fishery Investigations. Proc. 1931-1933, No. 2, King's Printer, Ottawa, 40 p. NAFO. 1980. Annual report for the year 1979. NAFO Ann. Rep., 1, $86 \mathrm{p}$. 1983. Report of ad hoc working group on herring tagging. NAFO Sci. Coun. Rep., 1983: 77-101. 1985. Report of Scientific Council. NAFO Sci. Coun. Rep., 1985: 103-121. 1986a. Report of Scientific Council. NAFO Sci. Coun. Rep., 1986: 27-105. 1986b. Report of Scientific Council. NAFO Sci. Coun. Rep., 1986: 107-130. MS 1986. Report of the General Council. NAFO GC Doc., No. 4 (Revised), Serial No. N1268, 30 p. 1989. Report of Scientific Council. NAFO Sci. Coun. Rep., 1989: 9-134.

NEEDLER, A. W. H. (Undated). Report on a biological study of fishery statistics of the Atlantic coast of Canada. Biol. Board Can., Man. Rep., No. 97, 52 p. + figs.

1930. The migrations of haddock and the interrelationships of haddock populations in North American waters. Contrib. Can. Biol. Fish., (New Ser.), 6(10): 241313.

MS 1952. The biologists' need for fisheries statistics. ICNAF Meet. Doc., No. 6B, Serial No. 48, 6 p.

NEILSON, J. D., E. M. DeBLOIS, and P.C.F. HURLEY. 1988. Stock structure of Scotian Shelf flatfish as inferred from ichthyoplankton survey data and the geographic distribution of mature females. Can. J. Fish. Aquat. Sci., 45: 16741685.

PITT, T. K. 1969. Migrations of American plaice on the Grand Bank and in St. Mary's Bay, 1954, 1959, and 1961. J. Fish. Res. Board Can., 26: 1301-1319.

POULSEN, E. M. MS 1953. Boundaries of the Convention Area, of its Subareas, and of their Subdivisions, p. 14-19. In: Côté, J., Statistical requirements of the International Commission for the Northwest Atlantic Fisheries. ICNAF letter dated 1 Aug. 1953, Serial No. 132, 22 p.

POWLES, P. M. 1965. Life history and ecology of American plaice (Hippoglossoides platessoides F.) in the Magdalen Shallows. J. Fish. Res. Board Can., 22: 565-598.

$\mathrm{RICH}$, W. H. 1929. Fishing grounds of the Gulf of Maine. App. 2 to Report of the U.S. Commissioner of Fisheries for 1929. U.S. Bur. Fish., Doc. 1059, Government Printing Office, Wash., D.C.: 51-114.

ROUNSEFELL, G. A. 1948. Development of fishery statistics in the North Atlantic. US Fish. Wildl. Serv. Spec. Sci. Rep., 47, $27 \mathrm{p}$.

1957. A method of estimating abundance of groundfish on Georges Bank. Fish. Bull. U.S., 57: 263-278.

SCHMIDT, J. 1931. Summary of the Danish marking experiments on cod, 1904-1929, at the Faroes, Iceland and Greenland. ICES Rapp. Proc.-Verb., 72(3), 13 p.

SCHROEDER, W. C. 1930. Migrations and other phases in the life history of the cod off southern New England. Bull. U.S. Bur. Fish., 46, 136 p. (Doc. No. 1081).

1942. Results of haddock tagging in the Gulf of Maine from 1923 to 1932. J. Mar. Res., 5: 1-19.

SCHUCK, H. A., and E. L. ARNOLD. 1951. Comparison of haddock from Georges and Browns banks. Fish. Bull. U.S., 67: 177-185.
SCOTT, D. M., and W. R. MARTIN. 1957. Variations in the incidence of larval nematodes in Atlantic cod fillets along the southern Canadian mainland. J. Fish. Res. Board Can., 14: 975-996.

1959. The incidence of nematodes in the fillets of small cod from Lockeport, Nova Scotia, and the southwestern Gulf of St. Lawrence. J. Fish. Res. Board Can., 16: 213-221.

SCOTT, W. B., and M. G. SCOTT. 1988. Atlantic Fishes of Canada. Can. Bull. Fish. Aquat. Sci, 219, 731 p.

SETTE, O. E. 1950. Biology of the Atlantic mackerel (Scomber scombrus) of North America. Part 11 - migrations and habits. Fish. Bull. U.S., (49)51: 251-358.

SHEPHERD, J. G. 1988. Fish stock assessments and their data requirements, p. 35-62. In: Gulland, J. A. (ed.), Fish PopuIation Dynamics, Second Edition. John Wiley and Sons, Chichester, $422 \mathrm{p}$.

SINCLAIR, M. 1988. Marine populations. An essay on population regulation and speciation. Washington Sea Grant/ University of Washington Press, Seattle, $252 \mathrm{p}$.

SINCLAIR, M., and P. SOLEMDAL. 1988. The development of "population thinking" in fisheries biology between 1878 and 1930. Aquat. Living Resour., 1: 189-213.

SINCLAIR, M., R. K. MOHN, G. ROBERT, and D. L. RODDICK. 1985a. Considerations for the effective management of Atlantic scallops. Can. Tech. Rep. Fish. Aquat. Sci., 1382, $120 \mathrm{p}$.

SINCLAIR, M., V. C. ANTHONY, T. D. ILES, and R. N. O'BOYLE. 1985b. Stock assessment problems in Atlantic herring (Clupea harengus) in the Northwest Atlantic. Can. J. Fish. Aquat. Sci., 42: 888-898.

STOBO, W. T., J. A. MOORES, and J. J. MAGUIRE. 1982. The herring and mackerel resources on the east coast of Canada. Can. Tech. Rep. Fish. Aquat. Sci., 1081, 27 p.

STOBO, W. T., J. D. NEILSON, and P. G. SIMPSON. 1988. Movements of Atlantic halibut (Hippoglossus hippoglossus) in the Canadian North Atlantic. Can. J. Fish. Aquat. Sci., 45: 484-491.

SULLIVAN, G. J. W., and W. R. MARTIN. 1955. 1951 landings of fresh groundfish by offshore vessels at Nova Scotia ports. Fish. Res. Board Can., Atl. Biol. Sta. Circ. (Stat. Ser.), 5, $12 \mathrm{p}$.

TÅNING, $\AA . \vee$. 1937. Some features in the migration of cod. ICES J. Cons., 12: 3-35.

TEMPLEMAN, W. MS 1952. Some migrations of cod on the Atlantic coast of Canada, p. 83-98 (App. F). In: Needler, A.W.H. Appendices to summary of Canadian research in the Convention Area. ICNAF Meet. Doc., No. 5E App., Serial No. 45, 111 p.

1953. Knowledge of divisions of stocks of cod, haddock, redfish and American plaice in Subareas 3 and 2 of the Northwest Atlantic Convention Area. ICNAF Ann. Proc., 3: 62-66.

1962. Division of cod stocks in the Northwest Atlantic. ICNAF Redbook, 1962(III): 79-123.

1970. Vertebral and other meristic characteristics of Greenland halibut, Reinhardtius hippoglossoides, from the northwest Atlantic. J. Fish. Res. Board Can., 27: 1549-1562

1974. Migrations and intermingling of Atlantic cod (Gadus morhua) stocks of the Newfoundland Area. $J$. Fish. Res. Board Can., 31: 1073-1092.

1979. Migration and intermingling of stocks of Atlan- 
tic cod, Gadus morhua, of the Newfoundland and adjacent areas from tagging in 1962-66. ICNAF Res. Bull., 14: $5-50$.

1981. Vertebral numbers in Atlantic cod, Gadus morhua, of the Newfoundland and adjacent areas, 1947-71, and their use for delineating cod stocks. J. Northw. Atl. Fish. Sci., 2: 21-45.

TEMPLEMAN, W., and C. A. BISHOP. 1979a. Sexual maturity and spawning in haddock, Melanogrammus aeglefinus, of St. Pierre Bank. ICNAF Res. Bull., 14: 77-83.

$1979 \mathrm{~b}$. Age, growth, year-class strength, and mortality of haddock, Melanogrammus aeglefinus, on St. Pierre Bank in 1948-75 and their relation to the haddock fishery of this area. ICNAF Res. Bull., 14: 85-99.

TEMPLEMAN, W., AND A. M. FLEMING. MS 1953. Proposed revision of division of Subareas 2 and 3. ICNAF Meet. Doc., No. 18, Appendix, Serial No. 90, 3 p.

1962. Cod tagging in the Newfoundland area during 1947 and 1948. J. Fish. Res. Board Can., 19: 445-487.

1963. Distribution of Lernaeocera branchialis L. on cod as an indicator of cod movements in the Newfoundland area. ICNAF Spec. Publ., 4: 318-322.

TEMPLEMAN, W., V. M. HODDER, and A. M. FLEMING. 1976. Infection of lumpish (Cyclopterus lumpus) with larvae and of Atlantic cod (Gadus morhua) with adults of the copepod, Lernaeocera branchialis, in and adjacent to the Newfoundland area, and inferences therefrom on inshore-offshore migrations of cod. J. Fish. Res. Board Can., 33: 711-731.

TEMPLEMAN, W., V. M. HODDER, and R. WELLS. 1978a. Age, growth, year-class strength, and mortality of the haddock, Melanogrammus aeglefinus, on the southern Grand Bank and their relation to the haddock fishery of this area. ICNAF Res. Bull., 13: 31-52.

1978b. Sexual maturity and spawning of haddock, Melanogrammus aeglefinus, of the southern Grand Bank. ICNAF Res. Bull., 13: 53-65.

TEMPLEMAN, W., H. J. SQUIRES, and A. M. FLEMING. 1957. Nematodes in the fillets of cod and other fishes in New- foundland and neighbouring areas. J. Fish. Res. Board Can., 14: 831-897.

THOMPSON, H. 1939. The occurrence and biological features of haddock in the Newfoundland area. Nfld. Dept. Nat. Resour. Res. Bull., 6, $31 \mathrm{p}$.

1943. A biological and economic study of cod (Gadus callarias, L.) in the Newfoundland area including Labrador. Nfld. Dept. Nat. Resour. Res. Bull., 14, 160 p.

TREMBLAY, M. J., R. MAHON, and R. O'BOYLE. 1984. Vertebral numbers in larval and juvenile haddock of the Scotian Shelf and implications for stock discrimination. J. Northw. Atl. Fish. Sci., 5: 213-217.

ULLTANG, $\emptyset$. 1977. Sources of errors in and limitations of Virtual Population Analysis (Cohort Analysis). ICES J. Cons., 37: 249-260.

USA. MS 1973. US comments and recommendations for establishing an adequate ICNAF data base. ICNAF Comm. Doc., No. 19, Serial No. 3066, 5 p.

MS 1974. Possible amendments to the Convention. Memorandum by the Government of the United States of America. ICNAF Comm. Doc., No. 9 + addendum, Serial No. $3243,4 p$.

MS 1975. US proposal on improved statistical reporting. ICNAF Comm. Doc. No. 28, Serial No. 3648, 2 p.

VLADYKOV, V. D. 1935. Haddock races along the North American coast. Biol. Bd. Can. Prog. Rep., 14: 3-7.

WHEELER, J. P., and G. H. WINTERS. 1984. Migrations and stock relationships of east and southeast Newfoundland herring (Clupea harengus) as shown by tagging studies. J. Northw. AtI. Fish. Sci., 5: 121-129.

WINTERS, G. H., and J. S. BECKETT. 1978. Migrations, biomass and stock interrelationships of Southwest Newfoundland - southern Gulf herring from mark-recapture experiments. ICNAF Res. Bull., 13: 67-79.

WISE, J. P. 1963. Cod groups in the New England area. Fish. Bull. U.S., 63: 189-203.

WISE, J.P., and A. C. JENSEN. MS 1960. Stocks of the important commercial species of fish of the ICNAF Convention Area. ICNAF Meet. Doc., No. 25, Serial No. 743,14 p. 


\section{Appendix 1}

A chronology of important changes in Northwest Atlantic fishing area boundaries, with text page references.

\begin{tabular}{|c|c|c|}
\hline Date & Event & Page No. \\
\hline 1891 & USA instituted systematic collection of area of capture information. & 2 \\
\hline 1932 & Delineation of statistical regions for the Northwest Atlantic by NACFI. & 4 \\
\hline $\begin{array}{l}1936 \\
\text { and } \\
1943\end{array}$ & Modification to NACFI boundary between Nova Scotia and New England regions. & 5 \\
\hline 1950 & $\begin{array}{l}\text { International Convention for the Northwest Atlantic Fisheries entered into force establishing ICNAF Convention } \\
\text { Area and Subareas. }\end{array}$ & 7 \\
\hline 1953 & ICNAF Commission established Division boundaries, effective 1 January 1954. & 10 \\
\hline 1958 & Divisions $3 \mathrm{P}$ and $4 \mathrm{~V}$ divided into northern and southern Subdivisions. & 18 \\
\hline 1967 & Division $5 Z$ divided into eastern and western Subdivisions. & 18 \\
\hline 1967 & Statistical Area 6, with Divisions A-H, delimited. & 20 \\
\hline 1974 & Statistical Area 0 established. & 20 \\
\hline 1975 & $\begin{array}{l}\text { ICNAF Commission approved statistical reporting by } 30^{\prime} \times 30^{\prime} \text { rectangles and twice-monthly time periods, } \\
\text { effective for } 1976 \text { statistics. }\end{array}$ & 28 \\
\hline 1977 & $\begin{array}{l}\text { Implementation of more detailed reporting deferred to avoid conflict with coastal state post-extension of juris- } \\
\text { diction requirements. }\end{array}$ & 28 \\
\hline 1978 & Statistical Area 0 extended and Divisions $A$ and $B$ established. & 21 \\
\hline 1979 & NAFO statistical grid established with boundaries identical to those of ICNAF. & 21 \\
\hline 1979 & $\begin{array}{l}\text { Boundary between Subareas } 0 \text { and } 1 \text { modified, effective } 1 \text { January } 1980 \text {, to coincide with Canada-Denmark } \\
\text { international boundary. }\end{array}$ & 21 \\
\hline 1986 & $\begin{array}{l}\text { Boundary between Divisions } 4 X \text { and } 5 Y \text { modified (in part) to correspond to Canada-USA international boundary, } \\
\text { effective } 9 \text { October } 1987 .\end{array}$ & 24 \\
\hline 1986 & $\begin{array}{l}\text { NAFO General Council agreed to record and report fisheries statistics separately by Canadian and USA parts of } \\
\text { Division } 5 Z \text {. Scientific Council created Subdivisions } 5 Z c \text { and } 5 Z u \text { for statistical reporting and publication } \\
\text { purposes. }\end{array}$ & 24 \\
\hline
\end{tabular}

